TORONTONIANS HAVE A NATURE PROBLEM - CAN BIOPHILIC DESIGN BE A SOLUTION?

AN INVESTIGATION INTO THE POTENTIAL OBSTACLES PREVENTING THE DEVELOPMENT AND IMPLEMENTATION OF BIOPHILIC DESIGN IN TORONTO.

by

\author{
Megan Easton \\ BA, Western University, 2017 \\ A Major Research Paper \\ presented to Ryerson University \\ in partial fulfillment of the requirements for the degree of \\ Master of Planning \\ in \\ Urban Development
}

Toronto, Ontario, Canada, 2019

(C) Megan Easton, 2019 
I hereby declare that I am the sole author of this MRP. This is a true copy of the MRP, including any required final revisions.

I authorize Ryerson University to lend this paper to other institutions or individuals for the purpose of scholarly research.

I further authorize Ryerson University to reproduce this MRP by photocopying or by other means, in total or in part, at the request of other institutions or individuals for the purpose of scholarly research.

I understand that my MRP may be made electronically available to the public. 


\title{
TORONTONIANS HAVE A NATURE PROBLEM - HOW CAN BIOPHILIC DESIGN BECOME THE SOLUTION?
}

\author{
AN INVESTIGATION INTO THE POTENTIAL OBSTACLES PREVENTING THE DEVELOPMENT \\ AND IMPLEMENTATION OF BIOPHILIC DESIGN IN TORONTO.
}

\author{
(C) Megan Easton, 2019 \\ Master of Planning \\ in \\ Urban Development \\ Ryerson University
}

\begin{abstract}
Biophilic design stems from the term biophilia; a concept that describes humans' innate connection and love for nature. It is an innovative way to bring nature into cities, reconnecting urban residents to the natural world through the built environment, while simultaneously contributing many mental, physical and environmental benefits. Despite extensive research on the significance of biophilic design, application in many urban environments, including Toronto, is minimal.

This paper investigates what, if any, obstacles may be preventing Toronto from integrating biophilic design. Research was conducted through a literature review, case study analysis and four key informant surveys. It finds that there are obstacles to local implementation including a lack of supportive planning framework, a lack of economic support and incentives, lacking professional expertise and absent demand. The paper acknowledges the literature, case studies and informant responses through the provision of recommendations that are designed to help the city overcome these obstacles.
\end{abstract}

Key words: Biophilia, Biophilic Design, Planning, Toronto 


\section{ACKNOWLEDGEMENTS}

I would like to sincerely thank Dr. Chris De Sousa for his continued support, guidance and enthusiasm throughout this major research paper. His strong academic background, research skills and insights around city greening greatly influenced and guided the research in this paper. His feedback helped improve the analysis and detail of the final product. I would also like to thank him for his humour and honesty throughout this process. He helped make the process both enjoyable and less stressful. I would also like to thank my second reader, Sheila Boudreau, whose insights, background, experience and ultimate feedback were greatly appreciated. 
AUTHOR'S DECLARATION FOR ELECTRONIC SUBMISSION OF A MRP ii

ABSTRACT iii

ACKNOWLEDGEMENTS iv

LIST OF FIGURES vii

CHAPTER 1: INTRODUCTION 1

1.1 Research Context - Urban Trends 1

1.2 Background - The Importance of Biophilia 1

1.3 Biophilic Design - An Opportunity for Greenery 2

1.4 The Lack of Application 3

1.5 The Toronto Context 3

1.6 Research Objectives $\quad 4$

1.7 Outline $\quad 4$

Chapter 2: METHODS

2.1 Research Sources $\quad 5$

2.2 Limitations $\quad 6$

CHAPTER 3: LITERATURE REVIEW

3.1 Biophilia and Its Benefits $\quad 8$

$\begin{array}{ll}3.1 .1 \text { Biophilia } & 8\end{array}$

3.2 Benefits of Biophilia 9

3.2.1 Physical and Mental Health 99

3.2.2 Intelligence and Creative Value 11

3.2.3 Humanity and Generosity 13

$\begin{array}{ll}3.2 .4 \text { Economic } & 14\end{array}$

3.3 Biophilic Design 16

3.3.1 What is Biophilic Design 17

3.4 Potential Obstacles to Implementation $\quad 19$

CHAPTER 4: CASE STUDIES 22

4.1 Various Case Studies for the Integration of Biophilic Design 22

4.1.1 Singapore 23

4.1.2 United States $\quad 34$

$\begin{array}{ll}\text { 4.1.3 Australia } & 38\end{array}$

4.2 Discussion 44

CHAPTER 5: SURVEYS

5.1 Awareness and Perceptions of Biophilic Design 49

5.2 Existing Successes and Challenges for Nature in Toronto 51 
5.3 Potential Change and Progress

5.4 14 Biophilic Design Principles 


\section{LIST OF FIGURES}

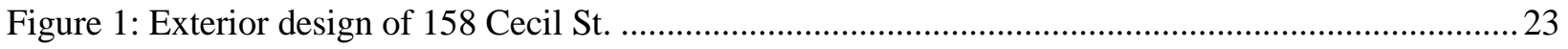

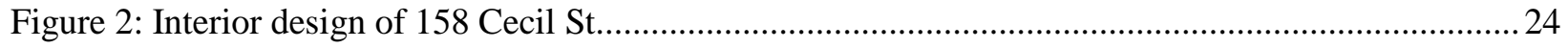

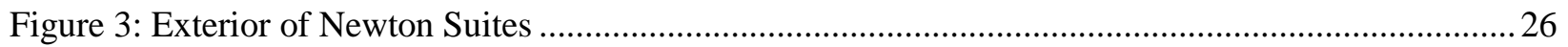

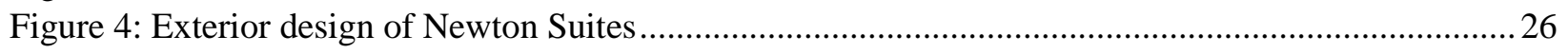

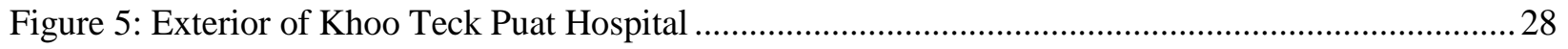

Figure 6: Surroundings of Khoo Teck Puat Hospital .........................................................................29

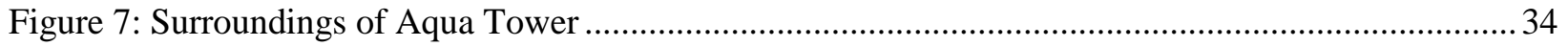

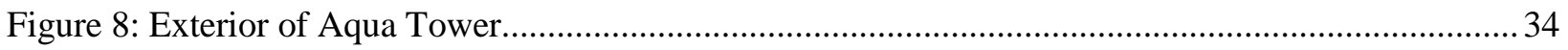

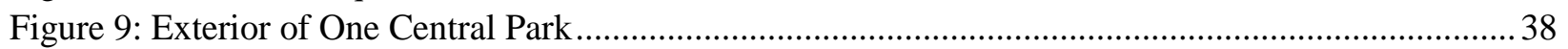


Quote: "We need creative design and urban planning that makes nature the centerpiece, not an afterthought”. (Beatley, 2010)

\section{CHAPTER 1: INTRODUCTION}

\subsection{Research Context - Urban Trends}

It is anticipated that the global urban population could increase by another 2.5 billion by 2050 . Megacities, those with more than 10 million people, are increasing steadily with India expected to have six by 2020 (United Nations, 2014). This is because more and more people are seeking to benefit from city's gathered economic and human resources that stimulate innovation, opportunity, growth and exposure to more goods and services. As a result, cities are experiencing rapid urbanization, ongoing development and increasing city densities. Although there are undoubtedly many benefits of population and city growth, such changes and trends spark parallel social, economic and environmental challenges in most cities (Young, 2016).

One of the challenges is maintaining exposure to quality greenery and nature in the city, two essential components of modern life (Beatley, 2017). This challenge is increasingly arising because accommodating heightened densities and growth is not typically associated with the provision or opportunity for ample green space and nature provision. More extremely, it more consistently leads to the popular attitude that if you want to have any meaningful exposure to nature, you should quickly exit the city (Beatley, 2011).

In order to address this trend, the provision of nature in cities will arguably need to go beyond existing provisions such as the city's existing parkland acquisition policies. It needs to instead be imagined in more profound ways, such that the two can co-exist alongside growth. As such, a key challenge for planning and design becomes conserving and restoring existing nature in cities while also creating new and innovative ways to insert nature forms back into the urban fabric. It is the latter that this major research paper (MRP) will focus on.

\subsection{Background - The Importance of Biophilia}

The significance of nature in cities stems from Edward O. Wilson's popularized concept of biophilia back in 1984. Wilson famously defines the term biophilia as the "innately emotional affiliation of human beings to other living organisms, innate meaning hereditary and hence part of the human nature" (Wilson, 1984; Beatley, 2017). The concept suggests that as a species, we are highly responsive to nature's forms, 
processes and patterns (Wilson, 1984). The coining of the concept led to ample research that has sought to confirm human preference for the natural over the built environment, and explore the many benefits provided by nature including its physical and mental health benefits, social, economic and environmental value (Kellert \& Wilson, 1993). These findings will be explored in more depth in Chapter 2.

Much of this interest and research in biophilia was prompted in response to rapid global urbanization. There was interest in investigating how increasing built infrastructure, physical barriers and the gradual elimination of distinct, large scale natural would disconnect people from the natural world, and more specifically, the impact it would have (Beatley, 2010). Additionally, much was prompted by prevailing human tendencies to spend more and more of their time inside, with a 2011 study suggesting that the average American spends $90 \%$ of their day indoors (Klepeis et al., 2001). This disconnection was explored further by Cox et al., (2017) who found that urban dwellers who interact with nature daily are now the exception, not the norm.

With the world's urban population expected to pass 6 billion by 2045 (UN, 2014) ensuring contact with nature is going to become increasingly important but also increasingly difficult (Beatley, 2011). The number of parks and open spaces can and are decreasing, while many rivers and soils are being paved over to accommodate more people (Birkeland, 2016). As a result, mitigating the impact and rate of rapidly declining green spaces is becoming more urgent.

\subsection{Biophilic Design - An Opportunity for Greenery}

Biophilic design represents one opportunity to increase nature and greenery in urban realms, with many known benefits. Biophilic design stems from the term biophilia and acknowledges how humans as a species are highly responsive to nature's forms, processes and patterns (Wilson, 1984). It provides an innovative way for designing the places where we live, work and play. It centers on integrating more nature within the built environment but more importantly focuses on how buildings and places can be designed to better connect people with nature.

Biophilic design has developed in recent decades as a practical way to integrate biophilia into increasingly densifying urban environments, like the City of Toronto. It represents a way to increase and maintain nature in urban areas that are dominated by glass towers, cement walkways and crowded spaces and struggling to integrate and sustain much-needed greenery alongside ongoing growth and densification (Bascaramurty, 2012; Kellert, 2016). It is not strictly an architectural style or aesthetic guide, but is a theory developed through scientific facts, empirical research and assessment of physical elements in space (Beatley, 2010). The importance of biophilic design is already clear. It represents both a solution and 
opportunity to create healthier and more productive habitats for modern humans, in environments that are becoming defined by densification and development.

\subsection{The Lack of Application}

Despite ongoing research, which highlights the ability for biophilic design to enhance people's contact with nature and ultimately increase the ability for people to live meaningful, happy, productive and healthy lives (Beatley \& Newman, 2013), there is an evident lack of tangible application throughout most urban environments today. Research until this point has focused heavily on the type of application and benefits provided by biophilia and biophilic design; however, few academics, architects and planners have taken the time to understand why biophilic design is still an exception rather than the norm.

Arguably, much of the problem stems from the modern notion that nature is still a resource to be exploited, or a nice but uncritical recreational and cultural amenity (Kellert, 2005), but it is anticipated that there are other obstacles. One theory extends from the debatably obsolete planning and design systems that define many urban cities. With this theory, part of the challenge in applying biophilic design and its benefits is contingent on advancing local systems, such that they begin to focus on minimizing some of the larger social, cultural, legal, economic and regulatory barriers to incorporation. That being said, there is still an overall lack of evidence, exploration and investigation into the obstacles impeding the consistent integration of biophilic design, especially at a contextual or local scale.

\subsection{The Toronto Context}

This research defines Toronto through the parameters delineated by the Toronto Official Plan Key Map. Toronto is among the largest cities in Canada and North America and is undoubtedly faced with balancing a mix of demands including housing, services, transit, parks, and an ongoing demand for built infrastructure (Grant, 2017). These demands are evidenced by local trends, where between 2001 and 2012 , the local population increased by over 200,000 , or $10 \%$, an amount that puts the city well ahead of estimations set out by the Toronto Official Plan (Lornic, 2015; Russo et al., 2017). This growth is not only increasing the development of residential and commercial towers across the city, but it is also increasing pressure on local park and environmental systems (Louv, 2012). Overtime, the city has been faced with a gradual decline in the amount of parkland per person, a concern for both maintaining the connection between humans and the natural world and for fostering a healthy and productive modern environment. 
As elsewhere in the urban world, Toronto can benefit from biophilic design to sustain, increase and creatively insert nature in the city while supporting and maintaining growth and development. Yet, despite a few new or contextual examples, Toronto has experienced minimal local application.

\subsection{Research Objectives}

The overall objective is to contribute to and investigate why or what is impeding the integration of biophilic design in Toronto through the question: What Obstacles are Preventing the Development and Implementation of Biophilic Design in Toronto?

This research study intends to fill a gap in existing scholarship through an investigation into specific and contextual obstacles for implementation. In order to draw more specific results, it will focus on obstacles to the application of biophilic design in Toronto to understand how the individual context, for example the local economy, planning context, environment or other factors, may or may not more specifically influence local application.

Aside from a few localized studies that have investigated challenges and constraints of biophilic design, such as those in Birmingham and Singapore, little research of this sort has been conducted (Newman, 2014; Littke, 2016). This research aims to target this thematic and contextual gap while also intending to further existing research.

\subsection{Outline}

Following this introduction, this paper is laid out in 6 additional chapters. Chapter 2 provides factual and contextual information on biophilia, biophilic design and its amounting benefits. It centers on summarizing existing literature and information surrounding why biophilic design is valuable, what benefits it can provide, and why it is worthy of research. Chapter 3 outlines and justifies the methodological approach employed in this research paper. Chapter 4 outlines and assesses the role of biophilic design through various global case studies. Chapter 5 then identifies and discusses key themes that emerged from key informant interviews. Finally, Chapter 6 provides a discussion, conclusion and a series of professional recommendations intended to suggest how Toronto could begin to overcome obstacles to the implementation of biophilic design. 


\section{Chapter 2: METHODS}

This paper provides an investigation into the obstacles facing the integration of biophilic design in Toronto. It seeks to summarize the importance of biophilic design, identify global use, application and trends, identify factors that may be impeding local application and finally, provide recommendations that may improve or guide future integration of biophilic design in the City of Toronto. It does this through three phases.

1. Literature and contextual overview

2. Global case study analysis

3. Survey of key informants

\subsection{Research Sources}

Research for this paper was contextualized by a foundational review of academic literature that identifies the application and benefits of biophilic design. Information was gathered and based on a combination of various manuscripts, newspaper articles, company and government documents.

This first stage of research sought to gather and summarize information about biophilic design. It provides a comprehensive understanding of the many social, economic, and environmental benefits of incorporation in the urban realm. It further focuses on identifying and consolidating what biophilic design is, what its benefits are, why it is worth exploring and what obstacles cities and countries globally may be facing. It also importantly identifies that despite ample research around the significance and role of biophilic design, there is still a lack of application, and only minimal literature to suggest why.

This study then employs a mixed method approach by way of both case study analysis and qualitative surveys of key informants. The goal through these sections is to investigate global and local trends in application and a lack there of. It further extends from the notion that if biophilic design is well researched and supported but not widely used, then its value and long-term implications becomes diminished.

A total of 6 global case studies were analyzed. Each of the cases utilize biophilic design at a different scale and in a different way. Each were assessed to identify how biophilic design was used, and how, if any, policy may be supporting the development or incorporation of biophilic design. Finally, each was compared against Bill Browning and Catie Ryan's 14 Patterns of Biophilic Design. These 14 Patterns of Biophilic Design were established by Terrapin Bright Green and identify ways to promote and create healthier and more productive built environments, while fostering enhanced linkages between humans 
and nature. In this paper, these patterns are used to identify any overarching trends in the use of biophilia and the application of biophilic design.

The purpose is to explore what policies, approaches, planning and motivations helped to guide integration and development of biophilic design in different places. These findings are eventually compared to Toronto in Chapter 6 in order to suggest why a lack of comparable motivations and approaches may be influencing the lack of biophilic design application in the city. The exploration of global policies and planning practices are also used to guide recommendations for the City of Toronto in Chapter 7.

Investigation into the obstacles facing the integration of biophilic design in Toronto was then conducted through key informant surveys. The surveys were designed to collect a range of vantage points from people who interact, engage and have awareness of biophilic design. In preparation for this primary data collection, this research sought and was granted Research Ethics Approval from Ryerson University.

A total of 4 surveys were completed involving key informants with a background in design, planning and development in the city. The surveys involved 18 open-ended and Likert scale questions with the intent of gathering opinion-based information on a relatively under researched and contextual topic.

The final Chapter of this paper provides conclusions and recommendations. This Chapter intentionally cross-references and consolidates the findings from the literature review, the case studies and the key informant interviews to identify how the city may overcome barriers to the implementation of biophilic design if desired.

\subsection{Limitations}

Limitations in this study include time and data. The number of key informant surveys were limited most directly by time. With more time, the surveys could have successfully targeted a larger diversity of responses from a larger range of professions across the city. To this regard, it is important to note that the 4 surveys utilized in this paper do not accurately represent the views of multiple or other professionals in Toronto. Nevertheless, the surveys do provide valuable insights into potential obstacles to implementation. They successfully provide a range of opinion and begin to identify contextual and local themes.

Due to a lack of existing research on obstacles to implementation the study also had to infer potential obstacles through the case studies. The case studies effectively highlight trends in use and application but do not specifically identify barriers, as such the study had to infer that a lack of said trends locally may represent possible obstacles. Notably; however, this study attempts to minimize the potential bias and 
limitations of inference by cross-referencing case study findings with obstacles identified in the literature review and key informant surveys. 


\section{CHAPTER 3: LITERATURE REVIEW}

This chapter focuses on understanding, exploring and highlighting existing literature with a specific focus on understanding what biophilia is, the role of nature in cities, and the overall benefits of nature in built environments. It will then explore what biophilic design is and how it offers a way to expand and explore the presence and impact of nature in modern built environments. Finally, this chapter will discuss possible obstacles to implementing biophilic design as discussed in the literature.

\subsection{Biophilia and Its Benefits}

\subsubsection{Biophilia}

As discussed in the introduction, the concept of biophilia was introduced by Edward O. Wilson in 1984. Wilson was a biologist, theorist and naturalist who defined and popularized biophilia as the human "urge to affiliate with other forms of life" (Wilson, 1984). Wilson proposed that humans have and sustain deep affiliations with other life forms and nature overall as a product of human biology and evolution (Wilson, 1984; Beatley, 2017). In contrast to phobias, philias refer to the attractions and positive feelings people have towards organisms, natural processes, surroundings and systems.

The concept of biophilia has since been researched by many academics, specialists and professionals who have sought to explore and justify the human-nature affiliation. This has led to the development of many conclusions and theories.

An ornithologist, Gordon H. Orians, suggests human attraction to the natural environment is at the DNA level, whereby human adaptations are based on experience and exposure to past environments (Orians, 2008). Orians suggests that human's innate affiliation to nature is based on historical evolvement to prefer to do and experience things that improve survival and reproductive success. In other words, humans desire wide-vista landscapes, water and coastal environments because they have delivered such advantages over our evolutionary history (Orians, 2008; Beatley, 2017).

In contrast, Stephen Kellert (2005) believes humans innate connection to nature is hardwired by way of "weak genetic tendencies". Kellert argues that this connection is maintained through cultural reinforcement and exercising rather than strictly natural phenomenon. Other professionals like Roger Ulrich and Judith Heerwagen have studied the human-biophilia relationship in terms of the capacity of biophilia to improve human well-being. Ulrich (1991) highlights that nature influences a positive shift in physiological activity, leads to the generation of positive emotions and increases sustained attention. His research explores the benefits of exposure that have developed from affiliation. 
The conclusions and theories of these individuals, although variable, consistently highlight human organisms need for direct experiences with nature. They each suggest that the concept of biophilia is multifaceted and undeniably important, but that the concept of biophilia is also not fully understandable.

Research has explored how and what constitutes biophilia and concludes that it can be seen and experienced at multiple levels or as Timothy Beatley (2010) suggests it can be seen above, below and all around us. For example, nature can be experienced through the wildlife and mammals that surround cities and the micro-organic life such as lichens, fungi and mosses that cover various surfaces (Preston, 2007). It can also be experienced through the sounds and sites of birds, rustling leaves, plant life and grasses that pervade various spaces and places and offer people temporary mental escapes into a different but tranquil world (Beatley, 2010).

Despite the many places that nature can and does thrive in urban environments, new development, urbanizing edges and rapid migration continue to challenge nature's ability to co-exist and thrive in cities. As such, more recent research has centered on exploring and explaining why nature is important and significant for human life (Beatley, 2017). While researchers such as Frederick Law Olmsted previously identified the value and role for parks, green spaces and nature in urban environments, more recent studies have analyzed and furthered findings to explore the wide range of positive benefits including, physical and mental health benefits and economic value among others.

\subsection{Benefits of Biophilia}

\subsubsection{Physical and Mental Health}

In the past few decades, among the most prominent and well researched areas of biophilia is the range of positive physical and mental health benefits provided by exposure to and contact with nature (Friedmann 1983, Frumkin 2001; Maas, Verheij et al., 2006; Frumkin, 2008; Grinde \& Patil, 2009; Beatley, 2011; Marcus and Sachs 2014; Beatley, 2017). Much of these studies and findings were extensions of Roger Ulrich's (1984) study on patients recovering from gall bladder surgery. This study conducted in Pennsylvania was among the first case examples proving the recuperative power of nature. The study assessed patients with and without nature views from their rooms and determined that those who resided in rooms that had direct views of trees, recovered faster and with less reliance on painkillers (Ulrich, 1984). Patients with a view of the outdoors also had less medication needs, more positive experiences with nurses and statistically shorter hospitalization periods.

Shortly after this study, a series of other, similar experiments were conducted to test his findings and assess people's psychological responses to varying natural scenes. Each study found that views of natural 
scenery led to improved recovery and psychological responses, relative to scenes of an urban or artificial environment (Frumkin 2001; Maas, Verheij et al., 2006).

Studies have also found the nature is associated with overall reductions in blood pressure, increased ability to recover from stress, illness and injury, and more laughter (Parsons, 1991; Ulrich, Simons \& Losito., 1991). One Chicago study for example found that public housing residents with greater access to landscaped natural areas indicated better mental health outcomes than those who had more access to or view of artificial, paved or hard surfaces (Kuo \& Sullivan, 1999).

These studies emphasize the ability for trees, nature, green space and other forms of nature to expedite healing, improve health and provide benefits in areas of physical and mental well-being. More recent studies have continued to validate these findings. One project conducted in the United Kingdom called The Mappiness Project asked study participants to indicate their self-reported levels of happiness via a phone application, every time they were prompted (MacKerron \& Mourato, 2013). Based on a geocoding of participant responses, it was found that the highest levels of happiness were consistently reported when participants were prompted in a natural setting.

In commonality, a study in Toronto that controlled for socio-economic factors, found a strong positive relationship between an urban blocks tree density and participants reported cardiometabolic illness and perceived health. City blocks with more trees correlated to participant responses that had less selfidentified ailments and higher reported health (Bullen, 2015; Kardan et al., 2015, Beatley, 2017). Significantly, the authors of this study also suggested that individuals living in areas that average just 10 more trees per block are likely to feel 7 years younger and \$10,000 richer (Bullen, 2015; Kardan et al., 2015). Further, studies around the significance of trees have also identified an inverse relationship between trees and a low birth rate (Donovan et al., 2011), a positive relationship between tree loss and mortality related to cardiovascular and lower respiratory-tract illness (Donovan et al., 2011), and a more positive outlook on life or higher life satisfaction when in proximity to trees and nature in otherwise urban places (Maas, Verheij et al., 2006; Grinde \& Patil, 2009).

The assessed physical and mental health benefits have also been studied relative to their specific implications on children. A study of 3,800 children found in the American Journal of Preventative Medicine found a significant positive relationship between the body mass index of children and the greenness of their neighbourhood (Bell, Wilson \& Liu, 2008). An alternate study focused on adolescents, found a strong relationship between park proximity and lower perceived stress levels (Feda et al., 2015). Furthermore, a study out of the University of British Columbia conducted earlier this year found children who grow up near or around vegetation are at $55 \%$ less risk of facing mental health disorders later in life 
(Nesbitt et al., 2019). Benefits have also been explored among work environments. A study published in the Health Environments Research and Design Journal found that nursing staff significantly benefitted from access to natural light in hospitals. It was noted that those with greater exposure to daylight throughout their shift had lower blood pressure ratings, improved social interactions among staff and most notably, more reported laughter (Zadeth, 2014).

More scientific studies pertaining to the psychological value of nature have also been conducted. Wang, Tsunetsugn and Africa (2015) have conducted extensive studies on what the Japanese refer to as shinrinyoku or 'forest bathing'. The studies focus on the significance of time spent walking in nature filled areas, specifically trees, and have identified significantly positive biophysical benefits. Reductions in the stress hormone cortisol and improvements to individuals' immune systems were among the most significant. The research collected was so significant that the Japanese government have since established multiple Forest Therapy Bases throughout the country to promote and attain these benefits across multiple cities. Interestingly these Forest Therapy Bases have helped attract many visitors who seek the physiological effects provided by these spaces. Furthermore, a study that monitored participants salivary cortisol levels to understand the impact of stress on individuals' circadian cycle of cortisol found that participants selfreported stress levels increased relative to reduced levels of green space (Roe \& Aspinall, 2011; Beatley, 2017).

Academic and scientific research highlights the growing evidence of that nature brings both physical and mental health benefits. This evidence was solidified in a 2009 study of nearly 2,000 people, which identified three broad health outcomes from participants exposure to green elements. Those being: 1) improved self-reported well-being of participants in areas like mood, depression and self-esteem, 2) physical health benefits such as reduced blood pressure, and 3) greater social networks (Barton \& Pretty, 2010). The research of Barton and Pretty (2010) was able to deduce that these positive effects, were for some, experienced after just five minutes.

Evidently, there is a breadth of findings across a wide range of research and sectors exploring the profound impact that nature can have on the physical and mental health of individuals. This impact can be attained regardless of age, ethnicity or social demographic and ultimately relies on ongoing exposure and opportune interaction in new and existing environments.

\subsubsection{Intelligence and Creative Value}

It is increasingly proven that exposure to nature enhances the intellectual and creative capacities of individuals. Two environmental psychologists Rachel and Stephen Kaplan started investigating the 
restorative powers of nature back in the 1980s. Their research was prompted in response to rapid technological advancement and ever-increasing indoor entertainment exhibited by urban societies and sought to explore the far-reaching consequences of directed attention and its resulting fatigue (Beatley, 2017). Investigation ultimately found that contact and exposure to nature is beneficial in recovering both mental fatigue and attention regardless of age (Kaplan, 1995). Their amounting Attention Restoration Theory emphasizes the rich characteristics that natural environments have in providing restorative experiences for individuals (Kaplan, 1995). Over time their studies have been extended to highlight the ability of nature to calm and focus the mind by offering a state that transcends relaxation, (Kaplan, 1995; Beatley, 2017) while increasing individual ability to focus, concentrate and restore energy (Clay, 2001; Han, 2003; Ohly et. Al, 2016).

There is now also evidence that nature has the specific capacity to intellectually benefit children. Multiple studies have proven that engagement and exposure to nature can significantly reduce symptoms of attention deficit disorder among youth (Kuo \& Taylor, 2003; Daley, 2010). A Michigan study of 101 public schools additionally concluded that the public schools with more views of nearby nature from their classrooms and lunch areas had higher overall standardized test scores and graduation rates (Matsuoka \& Kaplan, 2008).

Individual memory is also likely to increase from exposure to nature. A 2008 study found that after one hour of exposure to nature, participants memory performance and attention spans improved by $20 \%$ (Berman, 2008). Researcher, Mark Berman (2008), also emphasized the fact that individuals "do not have to enjoy the walk to get the benefits", suggesting exposure and interaction is beneficial regardless of people's preference or motivation. Berman's research highlights the innate benefits and capacities of nature, irrespective of individual preferences or preconceived notions, and identifies the ability for biophilia to act as natural, equally useable 'medicine' for people.

Australian researchers Cecily Maller et al., (2006) justify these benefits from a neurological perspective and suggest that nature experiences help restore functions of the brain overall, while particularly strengthening activities of the right side of the brain. This is because exposure, access to and views of nature relieves the brain of excess circulation and minimizes or relieves nervous system activity, which indirectly explains the idea of why people will 'go for a walk to clear their head' (Maller et al., 2006).

Natures capacity to restore and increase brain function also enhances individual creativity (Beatley, 2010; Beatley, 2017). A Danish study involving 17 qualitative interviews of creative professionals from varying demographics found that nature had two consistent impacts on participants. It increased individual curiosity, enhanced individual flexibility and ways of thinking, and it helped recharge individual attention 
to improve analysis and development of ideas, and idea generation (Plambech \& Kinijnendijk, 2015). More directly, other studies have found that individuals exposed to nature or even the colour green consistently perform better on creative oriented tasks (Atchley et al., 2012). Similar conclusions were found during a study that centered on kindergartens. It found that $16 \%$ of indoor kindergarten students invented new games, relative to $58 \%$ of outdoor kindergartens suggesting that the outdoor environment was far more effective at stimulating children's creativity (Louv, 2012).

A more natural environment appears to stimulate our ability to pay attention, enhances individual memory, and increase humans ability to think clearly and be more creative. The fact that ongoing research points to nature's ability to improve and engage our brains, adds legitimacy and urgency to the importance of preserving and adding natural features to our urban environments.

\subsubsection{Humanity and Generosity}

An increasing amount of research points to the capacity of nature to make us better, more nurturing people. Richard M. Ryan from the Institute for Positive Psychology and Education argues that, "people are more caring when they are around nature" as nature evokes more socially oriented feelings, promotes community value and supports the development of close-knit relationships (Ryan, 2000; Przybylski et al., 2009). Przybylski (2009) suggests this is because nature connects and reminds people of their authentic selves, or more indirectly connects people to historical human evolvement that depended on mutuality for survival. It similarly has been proven to make people more cooperative and compassionate (Zenenski, Dopko \& Capaldi, 2015; Beatley, 2017). A series of experiments conducted by Van der Wal et al. (2013) also showed that individuals who were exposed to nature rather than strict urban landscapes both valued and cared for the future more, and were less likely to delay gratification (Van der Wal, 2013; Beatley, 2017). Another study of over 2,000 people found that participants who spent a minute looking at eucalyptus trees reported feeling less entitled and self-involved than those who did not (Piff et al., 2015). Although not directly proven, much of this is attributed to the capacity for nature to reduce unpleasant feelings like fear, anger and stress, while simultaneously making people feel better emotionally.

Nature is also evidenced to improve humanity such that it can reduce local violence and crime (Weinstein et al., 2016; Boger \& Beyer, 2016). A study conducted in Chicago public housing found that women living in buildings with views of trees and greenery exhibited fewer aggressive and violent acts against their partners relative to women in identical buildings who had no view of greenery (Kuo \& Sullivan, 2001). Evidence highlights a reduction in anger and stronger interpersonal relationships (Frumkin, 2008). Similarly, a more recent study concluded an inverse relationship between local tree cover and crime, where all else being equal a " $10 \%$ increase in tree cover would be associated with an $11.8 \%$ decrease in 
the surrounding crime rate" (Troy, Grove \& O’Neil-Dunne, 2012). It appears that the amount of green space and natural elements positively impacts the safety of surrounding areas. In keeping with this theme, some studies have noted the consequences of a denatured life. Research suggests a lack of nature can increase feelings of aggression, increase local property crime, graffiti and litter, and decrease civility (Kuo, 2010; Buzzell, 2009).

The exact mechanism to explain the relationship between nature and reductions in crime and violence is still being theorized; however, many point back to the work of Jane Jacobs 'eyes on the street' in suggesting that nature encourages more people to spend time and be outside, leading to a greater degree of informal surveillance and thus reducing opportunities for criminal activity (Beatley, 2011). Kuo and Sullivan drew similar conclusions in their 2001 study that found that play areas with more trees had fewer incidences of violence. Although not validated, they suggest this could be because trees often attract a larger proportion of adults to an area.

With increasing sentiments of fear, distrust and anger among urban residents in recent years due to global and local concerns, sociologist Partick Sharkey believes there is no better time to get peoples 'eyes on the street' (Sharkey, 2018). Biophilic design and the nature it encompasses offers a valuable way to do this while simultaneously enhancing altruistic and kind behaviour, urban safety and well-being.

\subsubsection{Economic}

It can often be controversial to reduce nature to cents and dollars (Louv, 2012); however, equating money with value is often necessary to encourage people to justify and adopt various ideas. Notably, nature can assist in generating local wealth and economic sustainability, while also contributing to the sustainable functioning of natural ecosystems that humans depend on.

Nature; specifically trees, have been found to easily pay back the costs of growing and planting them (Beatley, 2017). A 2011 study in Tampa found that local trees save the city $\$ 35$ million a year due to respective savings in city services such as stormwater management, energy, soil erosion and public health (Landry et al., 2013). Findings in San Francisco suggest that local biophilia actually generates $\$ 959$ million annually because of similar savings (Trust for Public Land, 2014). The economic benefits of biophilia extend further into the market place. The property value of homes and properties that are located proximally to trees, parks and natural features can typically be sold for thousands of extra dollars relative to those that are not (Donovan \& Burty, 2010). Economic benefits have been extended to research in the retail community where Wolf (2005) found retail shoppers were willing to pay prices that were $25 \%$ more for shopping purchases in retail settings that contained more greenery. 
Much of the economic value of biophilia can also be attributed to indirect gains in employee productivity and absenteeism. In 2010, the reported absenteeism rate in the United States was 3\% per employee (62 working hours), $10 \%$ of that was found and attributed to work environments that were dominated by architecture that offered no connection to nature (Terrapin Bright Green, 2012). For large companies and organizations absenteeism amounts to many millions of dollars lost each year. Research also found that the presence of biophilia creates more 'high-performance' work places assisting cubicle bound workers by reducing symptoms of 'sick building syndrome' among others (Steinman, 1993). A professor at Carnegie Mellon suggests biophilia can reduce losses in work time, absenteeism and relative turnover rates, stating; 'retention of workers is a real issue, it costs employers about $\$ 25,000$ every time an employee leaves' (Louv, 2012). Similar studies have applied these concepts to school children, suggesting nature is correlated to test score improvements, increased learning ability and improved attendance, which carries significant economic value in both productivity and performance (Louv, 2012; Beatley, 2017).

These economic findings date back as early as Ulrich's 1984 study of gallbladder surgery patients discussed previously. Ulrich found that patients with a view of nature were released after an average of 7.96 days relative to the 8.71 days it took other patients (Ulrich, 1984). On the basis that the average cost per hospital day per patient was estimated at \$5,059 and applied to the 46 patients who participated in Ulrich's study, hospital savings would have amounted to $\$ 161,000$ among those participants alone (Terrapin Bright Green, 2012). From this study it is evident the economic value of that nature can have for different places.

Much of the economic savings provided by biophilia, extend from the environmental capacities it can provide. A study of this sort was conducted in Sacramento. Sacramento has a established a local Tree Foundation (STF), which has plans to initiate and support the planting of roughly 5 million new trees by 2025. In doing so, STF predicts that local temperatures could lower 3 degrees in the summer while up to 7 billion dollars of saving through stormwater management and air-pollution clean-up could be generated (Louv, 2012). Further, a Toronto study found that local trees provide residents with over 80 million dollars in environmental savings each year (TD, 2014). Specifically, it noted that for every dollar spent on annual urban forest maintenance, an average of $\$ 1.35$ - $\$ 3.20$ worth of benefits and cost savings resulted (TD, 2014). Extrapolating the proven impacts of biophilia in these studies provides a glimpse at the economic and environmental benefits that can come with biophilia in urban environments. It also highlights the capacity of natural elements to support the concept known as the triple bottom line.

Triple bottom line importantly recognizes profits, return on investments and shareholder values of developments and businesses among other things, but extends traditional measures to include larger environmental and social dimensions (Slaper, 2011). In other words, social responsibility and 
environmental impact or what people and the planet need, become as important as economic value and help to outweigh the costs of implementation while supporting larger sustainability goals. Not only does nature and the integration of biophilia contribute to the traditional cost savings and value-add that people seek, but it also enhances the triple bottom line. It ultimately assists in enhancing the value of spaces and places, while providing extended positive impact.

The integration of biophilia transcends many sectors and provides ample proven benefits in areas of physical and mental health, humanity and well-being, and creativity, alongside many environmental and economic implications that enhance its appeal. Undoubtedly the integration of biophilia further enhances the functioning of natural systems, the sustainability of modern environments and local health by way of its fundamental purposes. Beyond the fact that human have evolved alongside and within nature and its systems, these benefits discussed highlight the value in making spaces and places greener through biophilic integration.

\subsection{Biophilic Design}

The past few decades have been characterized by technological advancement, vast rural to urban migration, increasing urban densities, and competition for land. As a result, development, building and design in urban spaces often has and continues to treat nature as a feature unworthy of consideration or as an obstacle to overcome (Kellert et al., 2008). This is reflected in existing environments that often lack adequate natural light, vegetation, ventilation, views and other beneficial contact with the natural world. According to Kellert and Finnegan (2011): "Much of the built environment today is so sensory deprived, it is sometimes reminiscent of the barren cages of an old fashion zoo, now ironically banned as “inhumane" (Kellert \& Calabrese, 2015).

The lack of nature in urban environments is problematic because of the evident qualities and benefits that nature provides. However, there are multiple human-design and constructed ways for nature to be integrated within urban environments. These approaches are conducive rather than in competition with the needs and development trends of urban environments. One of these approaches, arguably the most practical and innovative, is biophilic design.

The challenge of biophilic design is to address deficiencies of nature and biophilia in urban landscapes by establishing a new framework to incorporate it back into the contemporary and landscape practices of urban environments (Kellert 2005, Kellert and Finnegan 2011, Browning et al 2014; Beatley, 2017). 


\subsubsection{What is Biophilic Design}

While biophilia is the evident theory and constituting motive for the integration and importance of nature, biophilic design offers a tangible strategy to attain those benefits. A strategy to reconnect people to the natural world through the built environment (Kellert et al., 2008; Beatley, 2010). It is grounded in creating environments that advance peoples health and well-being as biological organisms while simultaneously advancing and contributing to the establishment of a quality modern city. By providing opportunities to advance natural qualities within and between buildings, it aims to reimagine city surfaces as ongoing opportunities to insert green life and natural features, and to then use these opportunities to provide improved visual and emotional connections between urban dwellers and nature (Beatley, 2012).

In order to successfully utilize biophilic design, there are a set of fundamental conditions that inform and direct basic practice. The principles are highlighted in the work of Stephen Kellert, a social ecology professor at Yale and Elizabeth Calabrese, a licensed architect and professor, in their work entitled The Practice of Biophilic Design (2015). These principles are driven by an inherent desire to sustain the quality, resilience and productivity of natural systems across various environments. They include:

1. Repeated and sustained engagement with nature;

2. Biophilic design focuses on human adaptations to the natural world that over evolutionary time have advanced people's health, fitness and wellbeing;

3. Biophilic design encourages an emotional attachment to particular settings and places;

4. Biophilic design promotes positive interactions between people and nature that encourage an expanded sense of relationship and responsibility for the human and natural communities;

5. Encourages mutual reinforcing, interconnected, and integrated architectural solutions

The goal is to ensure that biophilic design will support and help achieve the range of identified physical, mental and behavioural benefits, while also supporting the creation of sustainable natural communities and valuable ecological qualities of place. The ecological outcomes of the principles can be measured through shifts in a range of ecological services including nutrient cycling, soil and habitat formation, pollination, and the hydrological cycle, among others.

Alongside the development of these principles, the last decade has seen extensive research into the qualities, forms and types of nature that would be most beneficial and applicable to urban built environments. As a result, it has led to the publishing of many books (Kellert, Heerwagen \& Mador, 2011; Kellert \& Calabrese, 2015; Beatley, 2017), which have helped generate complementary versions around what comprises, constitutes and is indicative of biophilic design. Of the most readable and practical are a set of 14 Patterns of Biophilic Design outlined by Bill Browning and Catie Ryan, from the Terrapin Bright Green group shown below. 
1. Visual connection with nature - views of nature, living systems and natural processes.

2. Non-visual connection with nature - auditory, haptic, olfactory, or gustatory stimuli that engender a deliberate and positive reference to nature, living systems or natural processes.

3. Nonrhythmic sensory stimuli - a brief but welcome distraction around something special, stimulating, energizing and interesting.

4. Thermal and airflow variability - provide an environment that allows users to experience the sensory elements of airflow variability and thermal variability.

5. Presence of water - that enhances the experience of a place through the seeing, hearing or touching of water.

6. Dynamic and diffuse light - leverages varying intensities of light and shadow that change over time to create conditions that occur in nature and evoke feelings.

7. Connection with natural systems - awareness of natural processes, especially seasonal and temporal changes characteristic of a healthy ecosystem.

8. Biomorphic forms and patterns - symbolic references to contoured, patterned, textured or numerical arrangements that persist in nature.

9. Material connection with nature - material and elements from nature that, through minimal processing, reflect the local ecology or geology to create a distinct sense of place.

10. Complexity and order - rich sensory information that adheres to a spatial hierarchy similar to those encountered in nature (engaging and rich, balanced with boring).

11. Prospect - unimpeded view over a distance for surveillance and planning, feels open and free but maintains a sense of safety and control.

12. Refuge - feels safe, providing a sense of retreat and withdrawal - for work, protection, rest or healing - whether alone or in small groups.

13. Mystery - partially obscured views or other sensory devices that entice the individual to travel deeper into the environment.

14. Risk/peril - identifiable threat coupled with a reliable safeguard.

These 14 patterns offer a specified 'toolkit' for application that centers on the integration of direct and indirect nature experiences, alongside experiences of space and place. They outline how each can be achieved, integrated and envisioned. These patterns involve introducing vegetation to the urban landscape but also include elements that have no tangible link to nature or living systems such as organic forms and artistic representations (Downtown et al., 2016).

In applying and considering biophilic design and its application, it is imperative that the patterns and attributes are employed in a manner where they mutually enforce one another rather than appearing piecemeal or random (Kellert \& Calabrese, 2015; Beatley, 2017). The intent is that they will be experienced and enjoyed by way of multiple human senses, such that they will contribute to human enjoyment, comfort, satisfaction, individual cognitive performance and individuals overall natural experience (Kellert \& Calabrese, 2015).

Biophilic design is a developing theory, science and approach to the built environment. It is inspired by nature and its undeniable value for human life and the environment. Based on the identified benefits and need for nature in built environments, biophilic design becomes an opportunity to ensure that modern environments and larger urban areas are imbued with these benefits. 


\subsection{Potential Obstacles to Implementation}

This chapter has presented many strong arguments that highlight the power of nature and the importance of it in the built environment. It has demonstrated that there is a range of reasons for nature to be at the center of city planning and design and a more specific priority in city visions in the future. Despite this evidence, there are still obstacles to the wide-scale use and applicability of biophilic design in many urban settings. Obstacles identified in existing research and literature are discussed below.

\section{Bio-phobia}

Part of the challenge for wide scale biophilic design is that many people have become comfortable and used to being separate from nature in the city. Rather, many researchers and environmentalists suggest that an increasing number of people are actually exhibiting bio-phobia, a prejudice or fear of nature. Findings suggest modern day fears may extend beyond traditional themes of darkness, snakes and spiders and encompass anxieties such as a flock of birds or strong wind (Louv, 2008; Campbell, 2017). Part of the challenge to integrating biophilic design therefore stems from the everyday mindset of urban residents. People need to see themselves as part of the natural world and understand the beauty and wonder of other species and life forms (Beatley, 2017). Without this understanding, urban residents will be increasingly ignorant to the benefits and experiences of nature and exhibit an increasing lack of support and interest for policies and ideas that support it (Reeve et al., 2013).

\section{More Support from Planning and Policy}

Nature, in many cities, is still a secondary thought to the management and regulation of local development (Pincetl, 2012; Beatley, 2017). There is a gap and need for more ideas in which to guide nature growth, preservation and change in city environments. Of note is a need for specific tools and strategies that target the impact cities have on nature around the globe, to then enable cities to develop more specific green or sustainability codes to address this impact.

It additionally remains unclear what a biophilic development or planning code would look like or entail; however, for biophilic urbanism to pervade, this is something that needs more attention (Beatley, 2017).

\section{Differing Opinions on Aesthetic Design}

Individual and professional perceptions present an obstacle to biophilic design, where some people believe that elements like wide scale planting appears untidy and disorderly and is therefore an inappropriate addition to most modern architectural forms. Concerns are also raised about natures 
affiliation and ability to attract bugs, cause water-induced mold and potentially elevate surrounding humidity levels, when introduced to architectural spaces (Sole-Smith, 2006).

Much of these concerns extend from the mindsets of existing professionals. For example, a group of architectural professionals from the Singapore firm WOHA were asked about a new, local and nature-ful hotel called ParkRoyal. The majority of them reacted with little to no enthusiasm about the design or value of the space (Beatley, 2017). That being said, similar concerns and perspectives are mimicked by some urban residents who maintain a more rigid view of what constitutes aesthetically pleasing architectural form.

Some researchers suggest these concerns may stem from an overall lack of local research and data surrounding the proper integration and use of biophilic elements, that prevents decision makers, planners and designers from making informed, proper decisions (Reeve et al., 2013). From a cultural perspective, apprehension may extend from Joan Iverson Nassauer's (1995) concept “cues to care". This concept centers on the role of adapting cultural expectations to recognize new landscape forms that include elements of greater biodiversity. This is because ecological function is not necessarily recognizable by those who are not used to looking for it or are not aware of its benefits. Design needs to use cultural values to influence adoption and place new aesthetic styles like biophilic design into a familiar context. This becomes critical in shifting perceptions and gaining support for integration. Irrespective of motivation, a lack of positive opinions surrounding the significance and value of biophilic design will undoubtedly influence integration.

\section{A Lack of Quantifiable, Accessible Information on Nature's Benefits}

There is undoubtedly a large body of research that suggests the ample social, environmental and health benefits of utilizing biophilic design. However, there remains a lack of information identifying how to tap into these benefits to facilitate larger scale integration of nature in cities. Arguably, this is because it is difficult for people to quantifiably assess these benefits and understand that nature can be a good investment (Green, 2012; Stepnitz, 2013; Beatley, 2017). Some environmental economists have begun conducting triple bottom line analysis to assess environmental variables such as fossil fuel consumption, sulfur dioxide concentration, selected priority pollutants and change in natural land use or land cover with the goal of providing more tangible analysis of environmental factors. That being said, finding mechanisms to measure and capture the specific benefits of biophilic design remain relatively intangible, making it difficult for people to latch onto the concept and compare it against other opportunities.

\section{A Lack of Expertise, Knowledge and Willingness to Change}


Biophilic design is sill an emerging planning and architectural approach where some applications, principles and patterns are not yet entirely understood. There is concern that we may not know enough about the ecological effectiveness of biophilic design strategies and further may not know enough about the actual design of features like vertical walls to effectively and realistically implement them (Beatley, 2017; McLennan, 2019). Research and academic literature in this area continues to grow, but these concerns certainly have major implications for guiding biophilic design and planning into the future.

Difficultly also stems from a lacking desire to change. As noted by Laggards (1964) Diffusion of Innovation curve, ideas and concepts often gain momentum and then spread through a population before being adopted as a new idea or behaviour (LaMorte, 2018). Even if people are aware of a concept or have the information to implement it, adoption is often limited until it becomes a reoccurring pattern in a social system. Given that biophilic design is still emerging, people may be apprehensive to adopt and implement it, until it becomes more diffused within society.

\section{Economic Viability}

There is still a need to determine how to creatively finance the various components of biophilic design including development and maintenance. The expertise, costly materials, innovation and time required to implement biophilic design increases costs in terms of money and time (Ryan, 2017). These increased costs then raise fees for users of the space, making such building largely possible only for high-end clients.

In order to make biophilic design more accessible, there needs to be greater focus on raising capital, providing additional funding for private entities, while enhancing opportunities for active participation and education (Beatley, 2017). Further, financing strategies need to ensure that additional costs of development and maintenance are equally borne by multiple stakeholders as the benefits of biophilic design are experienced by many. If traditional models do not value the externalities created by biophilic design then they will continue to disempower decision makers from including biophilic elements in urban and building design (Reeve et al., 2013).

The six obstacles discussed above represent challenges that any city around the world may face in the shift to implementing biophilic design in their urban realm. They each shed light onto why, despite the many discussed benefits, biophilic design does not pervade many urban environments including Toronto.

This chapter provided an overview on the significance of biophilic design. It explored the various environmental physical and mental health benefits, identified and explored what constitutes biophilic design and how it is applied and concluded with an exploration into potential obstacles to 
implementation. It is clear that biophilic design has the ability to not only increase the abundance and exposure to natures in city's but also has the capacity to provide countless other benefits for human wellbeing and development.

Despite evident recognition of the significance of biophilic design and initial exploration into possible obstacles, there is minimal literature on the impediments to implementation at a local scale. The primary goal of the following chapters is to explore this gap through a local Toronto context, to extend upon the obstacles referenced above and discuss through primary and secondary research what may be specifically hindering local application of biophilic design.

\section{CHAPTER 4: CASE STUDIES}

\subsection{Various Case Studies for the Integration of Biophilic Design}

With ongoing research into the potential integration and significance of biophilic design, various cities have begun to integrate biophilic design within their planning, design and development realms to spur integration. Each have applied and utilized it at differing scales and intensities. This Chapter will highlight some global applications of biophilic design, overviewing both their key design features and 
relevant, supporting policy. Each case example will then be assessed against Bill Browning and Catie Ryan's 14 Patterns of Biophilic Design. The intent is to broadly identify how the design approach of each case study does or does not explicitly achieve each pattern and its respective purpose. The description of how each pattern is utilized in each case study does not encompass all aspects of integration but seeks to identify some of the ways each case has successfully and differently achieved each pattern in their design. This assessment table will also be used to help ground the discussion at the end of the Chapter.

\subsubsection{Singapore}

158 Cecil Street, Singapore

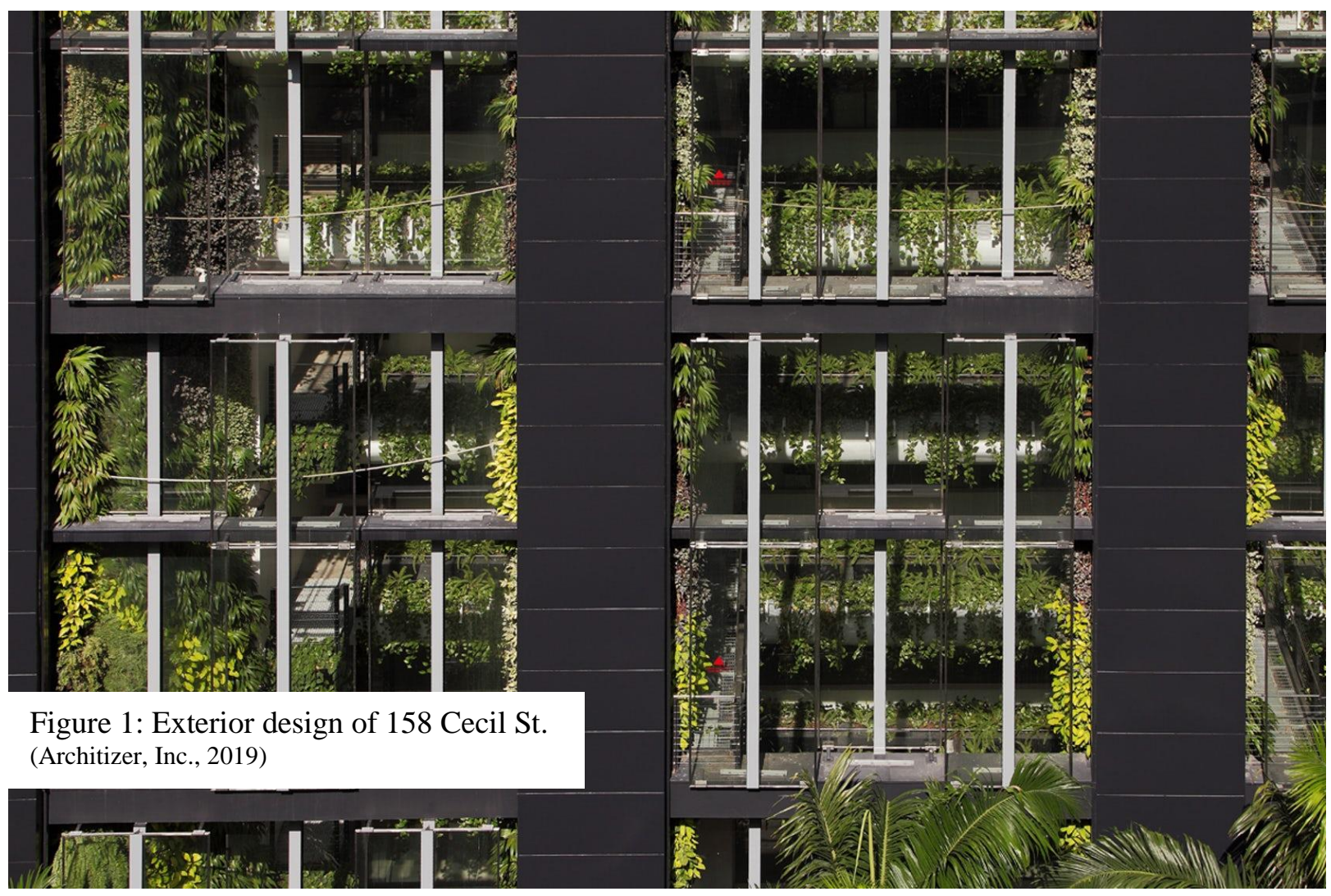




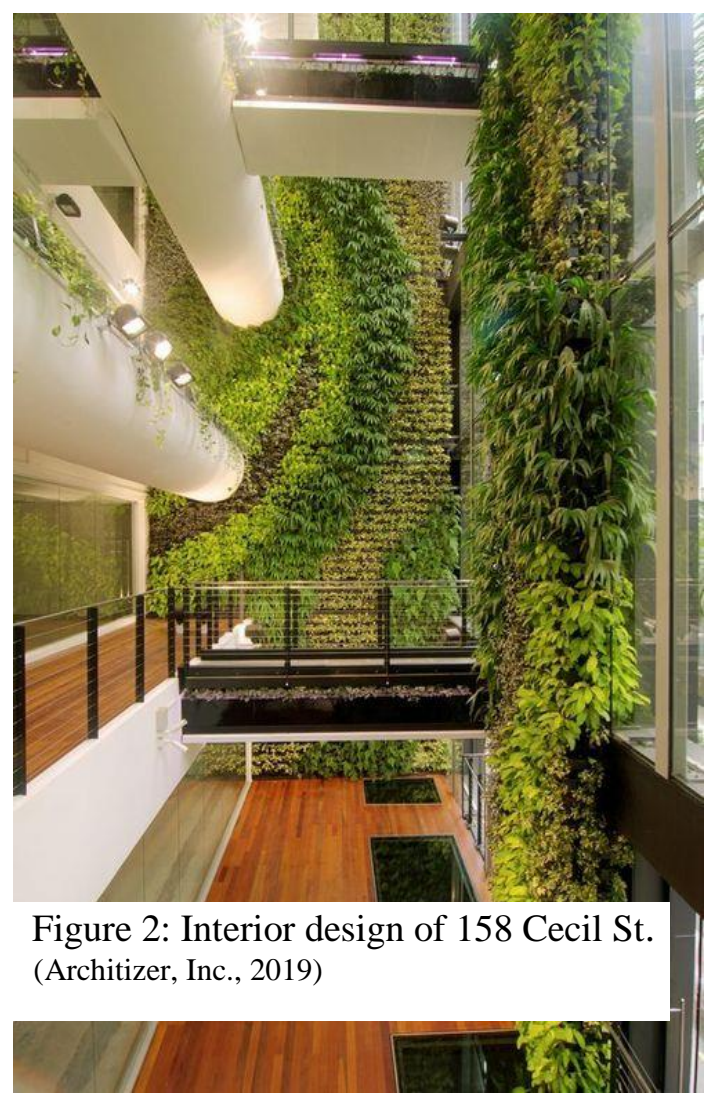

The 14-storey commercial building at 158 Cecil Street recently added a green wall to create a 'hanging structure' to effectively enhance the existing structure that was both ugly and impractical. The wall introduced 13,000 plants into a $350 \mathrm{~m}^{2}$ area alongside additional hanging plants on building balconies (Architizer, 2019). Each part of the wall is easily accessible, such that each plant can be individually tended to or replaced to make maintenance more efficient and easier. Upon completion, the wall has provided refuge to a variety of birds and butterflies, increased natural ventilation on site and notably introduced a valued work of art into a structurally heavy environment. It has also helped increase the appeal and rental demand of the space, with many companies seeking to relocate into this building to reap its benefits. It was also noted that existing tenants began orienting their offices and work spaces towards the green wall (Architizer, 2019).

\begin{tabular}{|l|l|l|}
\hline Pattern & Purpose & Utilized \\
\hline $\begin{array}{l}\text { Visual connection with } \\
\text { nature }\end{array}$ & $\begin{array}{l}\text { To stimulate pleasure, prolonged interest } \\
\text { and faster stress recovery by increasingly } \\
\text { grabbing one's attention, stimulating the } \\
\text { mind and creating a sense of respite and } \\
\text { ease. }\end{array}$ & $\begin{array}{l}\text { X-Green wall, hanging plants and } \\
\text { balcony greening. }\end{array}$ \\
\hline $\begin{array}{l}\text { Non-visual connection with } \\
\text { nature }\end{array}$ & $\begin{array}{l}\text { To introduce complex variable sounds } \\
\text { that are also familiar and comfortable } \\
\text { with the goal of contributing to mental } \\
\text { health, cognitive performance and more } \\
\text { targeted reductions to stress hormones. }\end{array}$ & $\begin{array}{l}\text { X-Textured materials and green } \\
\text { wall that extended presence of birds, } \\
\text { butterflies and other audible species. }\end{array}$ \\
\hline Nonrhythmic sensory Stimuli & $\begin{array}{l}\text { Evolved from behaviour-based research, } \\
\text { with a goal of supporting relaxation, } \\
\text { improved attention and broader } \\
\text { physiological restoration. }\end{array}$ & $\begin{array}{l}\text { X-Rustling of plants introduced, } \\
\text { movement of surrounding species } \\
\text { that is combined with fragrant new } \\
\text { trees and plants. }\end{array}$ \\
\hline $\begin{array}{l}\text { Thermal and airflow } \\
\text { variability }\end{array}$ & $\begin{array}{l}\text { To enhance worker comfort, well-being, } \\
\text { productivity and localized temporal and } \\
\text { spatial pleasure. By moderating sensory } \\
\text { variability this element aims to address } \\
\text { issues or boredom and passivity. }\end{array}$ & $\begin{array}{l}\text { X-Evapotranspiration from local } \\
\text { plants cools surrounding } \\
\text { temperatures, while dispersing } \\
\text { surrounding air currents, increased } \\
\text { shadows and shading within. }\end{array}$ \\
\hline Presence of Water & $\begin{array}{l}\text { Evokes positive emotional responses and } \\
\text { visual preferences while contributing to } \\
\text { enhanced feelings of comfort, relaxation } \\
\text { and general emotional responses. }\end{array}$ & \\
\hline
\end{tabular}




\begin{tabular}{|c|c|c|}
\hline Dynamic and diffuse light & $\begin{array}{l}\text { Contributes to improved performance, } \\
\text { mood and well-being while also } \\
\text { improving body temperature, heart rate } \\
\text { and circadian functioning. }\end{array}$ & $\begin{array}{l}\mathrm{X}-\text { Large windows enabling access } \\
\text { to daylight, and direct sunlight at } \\
\text { multiple glares and distributions. }\end{array}$ \\
\hline $\begin{array}{l}\text { Connection with natural } \\
\text { systems }\end{array}$ & $\begin{array}{l}\text { Suspected to enhance and improve health } \\
\text { responses with a particularly strong } \\
\text { temporal element. }\end{array}$ & $\begin{array}{l}\mathrm{X}-\text { Enhanced exposure to } \\
\text { surrounding animals. Diurnal } \\
\text { patterns and seasonal patterns of the } \\
\text { local environment. }\end{array}$ \\
\hline $\begin{array}{l}\text { Biomorphic forms and } \\
\text { patterns }\end{array}$ & $\begin{array}{l}\text { To symbolically represent natural life } \\
\text { forms as a way to shift focus, and } \\
\text { enhance concentration, allowing users to } \\
\text { draw connections to nature. }\end{array}$ & \\
\hline $\begin{array}{l}\text { Material connection with } \\
\text { nature }\end{array}$ & $\begin{array}{l}\text { Attempting to draw on improved } \\
\text { psychological responses to natural } \\
\text { materials and colors as a means to } \\
\text { integrate their role on enhanced cognitive } \\
\text { performance. }\end{array}$ & \\
\hline Complexity and order & $\begin{array}{l}\text { To strike a balance between boring and } \\
\text { overwhelming, to avoid added stress, } \\
\text { convey order and minimize physiological } \\
\text { tension. }\end{array}$ & \\
\hline Prospect & $\begin{array}{l}\text { Developed from psychology and } \\
\text { architectural analysis, the goal is to } \\
\text { promote reductions in stress, fatigue, } \\
\text { perceived vulnerability, while enhancing } \\
\text { comfort. }\end{array}$ & $\begin{array}{l}\mathrm{X} \text { - Provides open floor plans, clear } \\
\text { site lines, and views of and to } \\
\text { surrounding and introduced plants } \\
\text { and greening. }\end{array}$ \\
\hline Refuge & $\begin{array}{l}\text { Provide users with accessible, protective } \\
\text { environments in support of individual } \\
\text { restoration and comfort, improved } \\
\text { concentration, attention and general } \\
\text { feelings of safety. }\end{array}$ & \\
\hline Mystery & $\begin{array}{l}\text { Intended to heighten individual curiosity, } \\
\text { increase interest and local preference } \\
\text { while providing pleasure responses to } \\
\text { anticipatory situations. }\end{array}$ & $\begin{array}{l}\text { X - Introduces new scents, lights, } \\
\text { shadows and installations to evoke } \\
\text { emotions, simulate the mind and } \\
\text { foster movement. }\end{array}$ \\
\hline Risk/Peril & $\begin{array}{l}\text { Providing and awareness of controllable } \\
\text { risk, to introduce positive encounters that } \\
\text { then result in strong dopamine and/or } \\
\text { pleasure responses to surrounding } \\
\text { environments. }\end{array}$ & \\
\hline
\end{tabular}


Newton Suites, Singapore

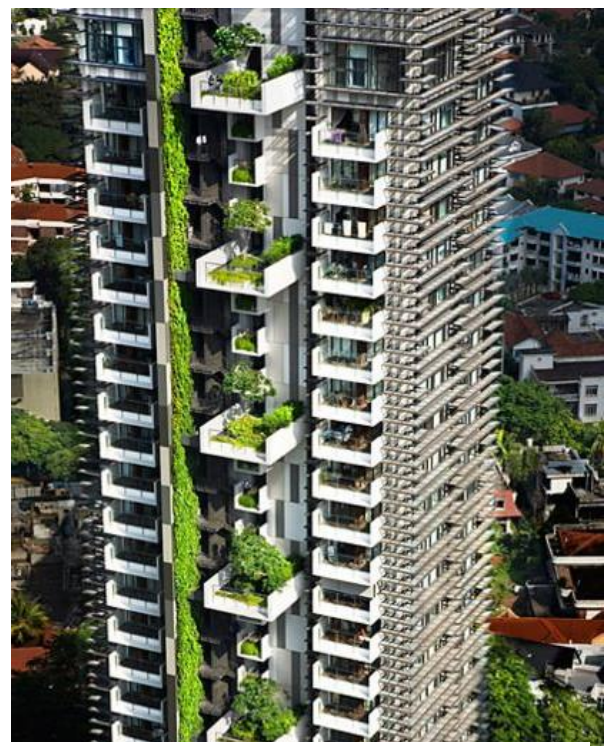

Figure 4: Exterior design of

Newton Suites (Architizer, Inc., 2019)
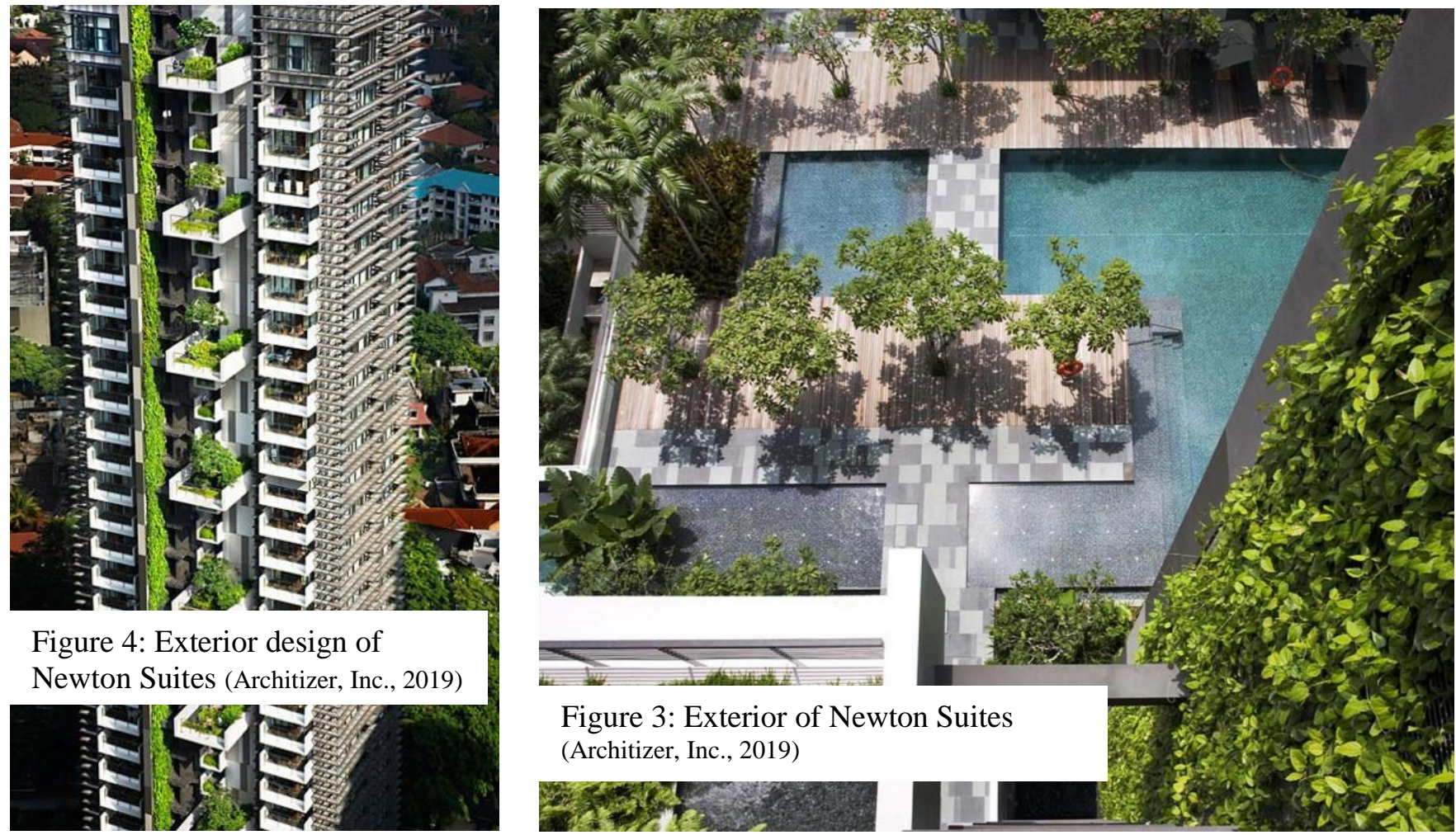

Designed by Architizer Architects in 2007, Newton Suites is a 36-storey high-rise condominium in the heart of Singapore that incorporates a variety of sustainable components. The building overlooks a heightcontrolled area, leading to expansive views of surrounding natural reserves. The exterior of the tower is comprised of sun shading elements and patterned planes to create a functional, yet expressive façade. Protruding sky gardens and balconies, green walls and rooftop planting further animate the space and create extensive outdoor living environments that were integrated into the building from the beginning (Architizer, 2007). The development also includes creeper screens and mesh pergolas to enhance the visual appearance of the design while simultaneously absorbing surrounding carbon and sunlight.

The combination of these material uses, and green elements create a lush green environment from ground to sky (Chiang \& Tan, 2009; Newman, 2012). The greenery acts as a key building material rather than an addition and amounts to a green area that covers $130 \%$ of the total developed area (Architizer, 2007). In 2008, the development also won the SIA-NParks Skyrise Greenery Award in recognition of the architects and builders' commitment to provisioning green elements throughout all stages of the buildings design. 


\begin{tabular}{|c|c|c|}
\hline Pattern & Purpose & Utilized \\
\hline $\begin{array}{l}\text { Visual connection with } \\
\text { nature }\end{array}$ & $\begin{array}{l}\text { To stimulate pleasure, prolonged interest } \\
\text { and faster stress recovery by increasingly } \\
\text { grabbing one's attention, stimulating the } \\
\text { mind and creating a sense of respite and } \\
\text { ease. }\end{array}$ & $\begin{array}{l}\mathrm{X}-\text { Green wall, hanging plants and } \\
\text { balcony greening combined with } \\
\text { exterior views. }\end{array}$ \\
\hline $\begin{array}{l}\text { Non-visual connection with } \\
\text { nature }\end{array}$ & $\begin{array}{l}\text { To introduce complex variable sounds } \\
\text { that are also familiar and comfortable } \\
\text { with the goal of contributing to mental } \\
\text { health, cognitive performance and more } \\
\text { targeted reductions to stress hormones. }\end{array}$ & \\
\hline Nonrhythmic sensory Stimuli & $\begin{array}{l}\text { Evolved from behaviour-based research, } \\
\text { with a goal of supporting relaxation, } \\
\text { improved attention and broader } \\
\text { physiological restoration. }\end{array}$ & $\begin{array}{l}\mathrm{X} \text { - Rustling of plants, lower } \\
\text { movement of water, reflections off } \\
\text { surrounding water. }\end{array}$ \\
\hline $\begin{array}{l}\text { Thermal and airflow } \\
\text { variability }\end{array}$ & $\begin{array}{l}\text { To enhance worker comfort, well-being, } \\
\text { productivity and localized temporal and } \\
\text { spatial pleasure. By moderating sensory } \\
\text { variability this element aims to address } \\
\text { issues or boredom and passivity. }\end{array}$ & $\begin{array}{l}\mathrm{X} \text { - Solar heat gain from plants, and } \\
\text { seasonal adaptations of plants. }\end{array}$ \\
\hline Presence of Water & $\begin{array}{l}\text { Evokes positive emotional responses and } \\
\text { visual preferences while contributing to } \\
\text { enhanced feelings of comfort, relaxation } \\
\text { and general emotional responses. }\end{array}$ & \\
\hline Dynamic and diffuse light & $\begin{array}{l}\text { Contributes to improved performance, } \\
\text { mood and well-being while also } \\
\text { improving body temperature, heart rate } \\
\text { and circadian functioning. }\end{array}$ & $\begin{array}{l}\mathrm{X} \text { - Large windows enabling access } \\
\text { to daylight, and direct sunlight at } \\
\text { multiple glares and distributions. }\end{array}$ \\
\hline $\begin{array}{l}\text { Connection with natural } \\
\text { systems }\end{array}$ & $\begin{array}{l}\text { Suspected to enhance and improve health } \\
\text { responses with a particularly strong } \\
\text { temporal element. }\end{array}$ & $\begin{array}{l}\mathrm{X}-\text { Enhanced exposure to } \\
\text { surrounding plants, animals and } \\
\text { variations imposed by weather } \\
\text { changes. }\end{array}$ \\
\hline $\begin{array}{l}\text { Biomorphic forms and } \\
\text { patterns }\end{array}$ & $\begin{array}{l}\text { To symbolically represent natural life } \\
\text { forms as a way to shift focus, and } \\
\text { enhance concentration, allowing users to } \\
\text { draw connections to nature. }\end{array}$ & $\begin{array}{l}\mathrm{X} \text { - Introduction of sun shading } \\
\text { elements and patterned planes create } \\
\text { a functional, yet expressive façade. }\end{array}$ \\
\hline $\begin{array}{l}\text { Material connection with } \\
\text { nature }\end{array}$ & $\begin{array}{l}\text { Attempting to draw on improved } \\
\text { psychological responses to natural } \\
\text { materials and colors as a means to } \\
\text { integrate their role on enhanced cognitive } \\
\text { performance. }\end{array}$ & $\begin{array}{l}\mathrm{X}-\text { Patterned planes and accent } \\
\text { details to evoke positive emotions } \\
\text { and introduce a natural color palette } \\
\text { and distinct façade. }\end{array}$ \\
\hline Complexity and order & $\begin{array}{l}\text { To strike a balance between boring and } \\
\text { overwhelming, to avoid added stress, } \\
\text { convey order and minimize physiological } \\
\text { tension. }\end{array}$ & \\
\hline Prospect & $\begin{array}{l}\text { Developed from psychology and } \\
\text { architectural analysis, the goal is to } \\
\text { promote reductions in stress, fatigue, } \\
\text { perceived vulnerability, while enhancing } \\
\text { comfort. }\end{array}$ & $\begin{array}{l}\mathrm{X}-\text { Enhanced access to balconies } \\
\text { and exterior greening. Elevated and } \\
\text { open floor plans designed to increase } \\
\text { exposure and views. }\end{array}$ \\
\hline Refuge & $\begin{array}{l}\text { Provide users with accessible, protective } \\
\text { environments in support of individual } \\
\text { restoration and comfort, improved } \\
\text { concentration, attention and general } \\
\text { feelings of safety. }\end{array}$ & $\begin{array}{l}\mathrm{X} \text { - Comfort provided through green } \\
\text { walls that separate interior and } \\
\text { exterior of the building from } \\
\text { surroundings, other people and } \\
\text { users. }\end{array}$ \\
\hline
\end{tabular}




\begin{tabular}{|l|l|l|}
\hline Mystery & $\begin{array}{l}\text { Intended to heighten individual curiosity, } \\
\text { increase interest and local preference } \\
\text { while providing pleasure responses to } \\
\text { anticipatory situations. }\end{array}$ & $\begin{array}{l}\text { X-Increased movement, sounds } \\
\text { and natural scents provided on and } \\
\text { surrounding the site. Windows help } \\
\text { reveal and expose people to distinct } \\
\text { features. }\end{array}$ \\
\hline Risk/Peril & $\begin{array}{l}\text { Providing and awareness of controllable } \\
\text { risk, to introduce positive encounters that } \\
\text { then result in strong dopamine and/or } \\
\text { pleasure responses to surrounding } \\
\text { environments. }\end{array}$ & \\
\hline
\end{tabular}

\section{Khoo Teck Puat Hospital, Singapore}

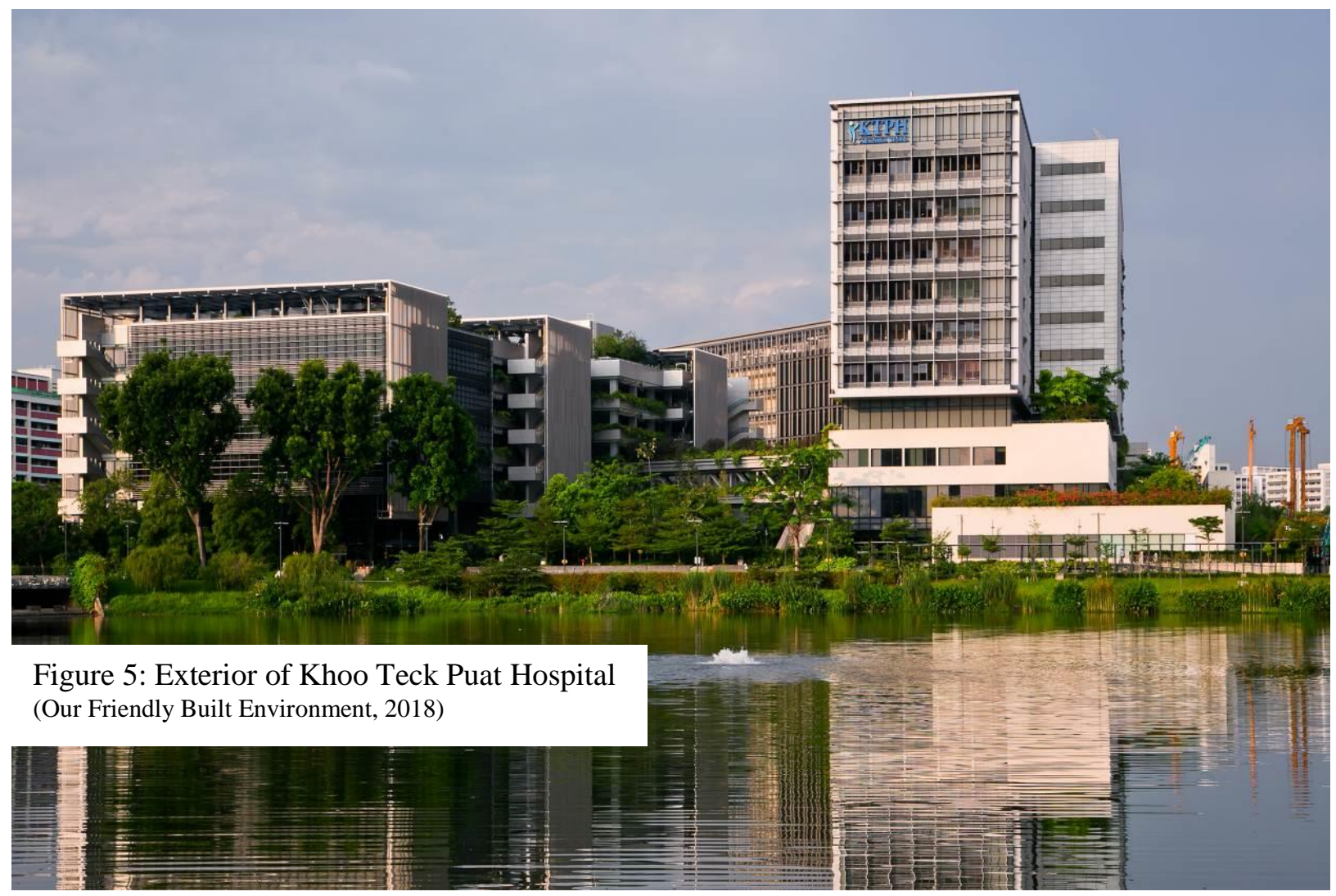


The 550-bed Khoo Teck Puat (KTP) hospital in Yishun, Singapore opened in 2010 and is the first biophilic hospital in the world with a goal, as highlighted by CEO Liak Teng Lit, to make the site less "clinical, drab and boring" (ILFI, 2019). The exterior of the building was designed in a $\mathrm{V}$-shape to capitalize on breezes and natural airflow

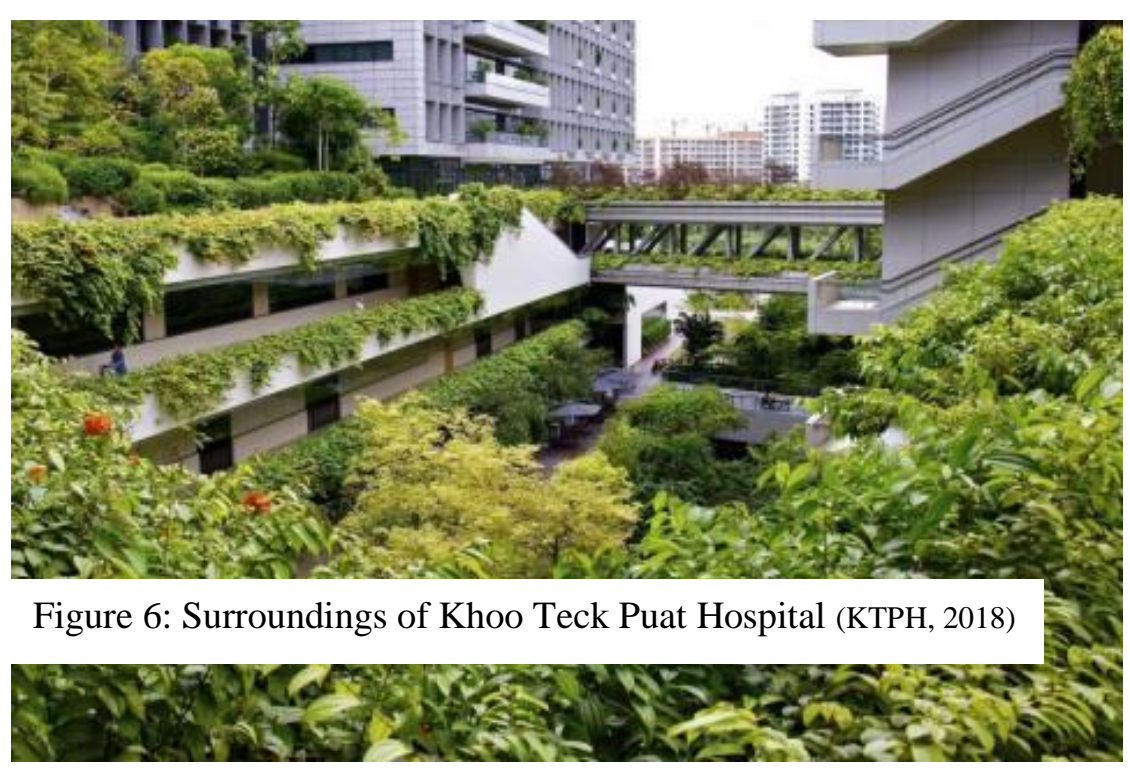
around the site. Common areas like the public corridors and the main lobby were planned for optimal ventilation and reduced reliance on energy. Roof gardens and farming on-site add engaging and educational greenery to the area while also developing 200 varieties of produce for use by the hospital kitchen (KTPH, 2019).

The site also includes many water features, a fragrance and medicinal garden, and ample trees, which attract many species of birds and butterflies. Scented plants are intentionally included to ensure the qualities of nature are experienced right by patient's bedside. These features have collectively amounted to on-site greenery that is nearly four times the size of the hospital's land surface (Newman, 2012).

Through collaboration with government agencies the site has adopted the adjacent storm water pond to expand their blue-green footprint and serve a greater public purpose on site. The addition of the pond and associated plants, water and walking trails, increased the green space available to hospital patients by $400 \%$ (ILFI, 2017). Features within the hospital have further helped capture and reuse $12 \%$ of rainwater runoff, have reduced energy consumption by $30 \%$ compared to other new hospitals and contribute to roughly one million dollars in savings per year (Newman, 2012).

The biophilic features of the hospital have been successful in providing a tranquil, communal space for the public, introducing therapeutic green spaces by way of a calming yet rejuvenating environment, enhancing patient comfort and their perceptions and feelings of well-being. It has become a popular destination for school and community group tours, and the general public who seek a relaxing, enjoyable environment. It was also noted that many staff have chosen KTP because of the unique ambience provided. As a site that fosters healing through innovative and extensive use of biophilic design, it is also the recipient of the first-ever Stephen R. Kellert Biophilic Design award (Newman, 2012). 


\begin{tabular}{|c|c|c|}
\hline Pattern & Purpose & Utilized \\
\hline $\begin{array}{l}\text { Visual connection with } \\
\text { nature }\end{array}$ & $\begin{array}{l}\text { To stimulate pleasure, prolonged interest } \\
\text { and faster stress recovery by increasingly } \\
\text { grabbing one's attention, stimulating the } \\
\text { mind and creating a sense of respite and } \\
\text { ease. }\end{array}$ & $\begin{array}{l}\mathrm{X}-\text { Green wall, hanging plants, roof } \\
\text { gardens, on-site farming and balcony } \\
\text { greening combined with exterior } \\
\text { views and landscaping. }\end{array}$ \\
\hline $\begin{array}{l}\text { Non-visual connection with } \\
\text { nature }\end{array}$ & $\begin{array}{l}\text { To introduce complex variable sounds } \\
\text { that are also familiar and comfortable } \\
\text { with the goal of contributing to mental } \\
\text { health, cognitive performance and more } \\
\text { targeted reductions to stress hormones. }\end{array}$ & $\begin{array}{l}\mathrm{X}-\mathrm{A} \text { fragrance and medicinal } \\
\text { garden, and ample trees, which } \\
\text { attract many species of birds and } \\
\text { butterflies. Scented plants on the } \\
\text { interior and exterior. }\end{array}$ \\
\hline Nonrhythmic sensory Stimuli & $\begin{array}{l}\text { Evolved from behaviour-based research, } \\
\text { with a goal of supporting relaxation, } \\
\text { improved attention and broader } \\
\text { physiological restoration. }\end{array}$ & $\begin{array}{l}\mathrm{X}-\text { Rustling of plants, water } \\
\text { movement and reflections, captured } \\
\text { and reused rainwater runoff. }\end{array}$ \\
\hline $\begin{array}{l}\text { Thermal and airflow } \\
\text { variability }\end{array}$ & $\begin{array}{l}\text { To enhance worker comfort, well-being, } \\
\text { productivity and localized temporal and } \\
\text { spatial pleasure. By moderating sensory } \\
\text { variability this element aims to address } \\
\text { issues or boredom and passivity. }\end{array}$ & $\begin{array}{l}\text { X-Solar heat gain from plants, and } \\
\text { seasonal adaptations of plants. Large } \\
\text { public corridors for enhanced flow } \\
\text { and variation. V-shape to capitalize } \\
\text { on breezes and natural airflow. }\end{array}$ \\
\hline Presence of Water & $\begin{array}{l}\text { Evokes positive emotional responses and } \\
\text { visual preferences while contributing to } \\
\text { enhanced feelings of comfort, relaxation } \\
\text { and general emotional responses. }\end{array}$ & $\begin{array}{l}\mathrm{X}-\text { Inclusion of a local pond and } \\
\text { surrounding stormwater pond to } \\
\text { enhance exposure and access to } \\
\text { flowing water. }\end{array}$ \\
\hline Dynamic and diffuse light & $\begin{array}{l}\text { Contributes to improved performance, } \\
\text { mood and well-being while also } \\
\text { improving body temperature, heart rate } \\
\text { and circadian functioning. }\end{array}$ & $\begin{array}{l}\mathrm{X} \text { - Large windows enabling access } \\
\text { to daylight, and direct sunlight at } \\
\text { multiple glares and distributions. }\end{array}$ \\
\hline $\begin{array}{l}\text { Connection with natural } \\
\text { systems }\end{array}$ & $\begin{array}{l}\text { Suspected to enhance and improve health } \\
\text { responses with a particularly strong } \\
\text { temporal element. }\end{array}$ & $\begin{array}{l}\mathrm{X}-\text { Enhanced exposure to } \\
\text { surrounding plants, animals and } \\
\text { variations imposed by weather } \\
\text { changes. }\end{array}$ \\
\hline $\begin{array}{l}\text { Biomorphic forms and } \\
\text { patterns }\end{array}$ & $\begin{array}{l}\text { To symbolically represent natural life } \\
\text { forms as a way to shift focus, and } \\
\text { enhance concentration, allowing users to } \\
\text { draw connections to nature. }\end{array}$ & $\begin{array}{l}\mathrm{X} \text { - Introduction of sun shading } \\
\text { elements and patterned planes create } \\
\text { a functional, yet expressive façade. }\end{array}$ \\
\hline $\begin{array}{l}\text { Material connection with } \\
\text { nature }\end{array}$ & $\begin{array}{l}\text { Attempting to draw on improved } \\
\text { psychological responses to natural } \\
\text { materials and colors as a means to } \\
\text { integrate their role on enhanced cognitive } \\
\text { performance. }\end{array}$ & $\begin{array}{l}\mathrm{X}-\text { Patterned planes and accent } \\
\text { details to evoke positive emotions } \\
\text { and introduce a natural color palette } \\
\text { and distinct façade to the interior and } \\
\text { exterior }\end{array}$ \\
\hline Complexity and order & $\begin{array}{l}\text { To strike a balance between boring and } \\
\text { overwhelming, to avoid added stress, } \\
\text { convey order and minimize physiological } \\
\text { tension. }\end{array}$ & $\begin{array}{l}\mathrm{X} \text { - Variety of natural and textured } \\
\text { wall coverings, exposed greening, } \\
\text { landscaped and planned floor levels } \\
\text { and pedestrian routes. }\end{array}$ \\
\hline Prospect & $\begin{array}{l}\text { Developed from psychology and } \\
\text { architectural analysis, the goal is to } \\
\text { promote reductions in stress, fatigue, } \\
\text { perceived vulnerability, while enhancing } \\
\text { comfort. }\end{array}$ & $\begin{array}{l}\mathrm{X}-\text { Enhanced access to balconies } \\
\text { and included greenings. Elevated } \\
\text { plans and open floor plans designed } \\
\text { to increase exposure and visuals. } \\
\text { Ample views of plants, trees and } \\
\text { water. }\end{array}$ \\
\hline Refuge & $\begin{array}{l}\text { Provide users with accessible, protective } \\
\text { environments in support of individual } \\
\text { restoration and comfort, improved }\end{array}$ & $\begin{array}{l}\mathrm{X}-\text { Provision of small protection } \\
\text { elements and refuge amidst large } \\
\text { green walls, canopy trees, covered } \\
\text { walkways and spaces. Varied light, }\end{array}$ \\
\hline
\end{tabular}




\begin{tabular}{|l|l|l|}
\hline & $\begin{array}{l}\text { concentration, attention and general } \\
\text { feelings of safety. }\end{array}$ & $\begin{array}{l}\text { temperature and brightness } \\
\text { providing therapeutic, tranquil green } \\
\text { spaces. }\end{array}$ \\
\hline Mystery & $\begin{array}{l}\text { Intended to heighten individual curiosity, } \\
\text { increase interest and local preference } \\
\text { while providing pleasure responses to } \\
\text { anticipatory situations. }\end{array}$ & $\begin{array}{l}\text { X-Increased movement, sounds } \\
\text { and natural scents provided on and } \\
\text { surrounding the site. Windows help } \\
\text { reveal and expose people to distinct } \\
\text { features while greening is carried } \\
\text { right through to the interior. }\end{array}$ \\
\hline Risk/Peril & $\begin{array}{l}\text { Providing and awareness of controllable } \\
\text { risk, to introduce positive encounters that } \\
\text { then result in strong dopamine and/or } \\
\text { pleasure responses to surrounding } \\
\text { environments. }\end{array}$ & $\begin{array}{l}\text { X-Varying heights, facades, and } \\
\text { floor planes that create an } \\
\text { immersive, uncontrollable } \\
\text { experience inside and out. }\end{array}$ \\
\hline
\end{tabular}

\section{Context for Biophilic Design in Singapore}

The establishment of enriched biophilia and biophilic design in Singapore is greatly influenced by larger political initiatives, policy development, and planning regulations that make greening the city a priority. The integration of biophilia was heavily influenced by the former Prime Minister Lee Kuan Yew who envisioned Singapore as a 'garden city' and believed it would help attract foreign investment and address air quality issues. It was furthered by Prime Minister Lee Hsien Loong who extended that vision to imagine Singapore as a 'city in a garden' (Newman, 2012).

A product of Yew's government, National Parks (NParks) was established as an extension of the local Ministry of National Development (NParks, 2019). It has since operated as a foundation for the creation of other green oriented policy and frameworks such as the Park Connector Network (PCN) and Skyrise Greenery. The PCN, although focused on overall park spaces and networks, fundamentally aims to create a complete 300km network of green connectors across the island (Newman, 2012; NParks, 2019). Through use of planned connections around spaces like the old regional rail alignment, Singapore had been successful in developing a 200km network by 2012. These developments not only serve to link central spaces throughout the city but also enrich 'greenery, conservation, education and recreation' (NParks, 2019).

NParks (2019) also encompasses a skyrise greening component as a more directive way to achieve sustainable urban development throughout the city. With a focus on rooftop and vertical greenery Skyrise Greenery will provide generous subsidies (up to 50\%) for installations of green walls, green rooftops, sky parks and terraces and other green elements of various sorts. The aim is to increase and encourage the presence of greenery in the built environment by assisting developers in the early phases of adoption. Singapore also promotes the integration of local biophilia through their planning regulations. The Singapore Green Plan (SGP) is grounded in developing green and sustainable places, with a goal to 
'bring spaces and biodiversity to [their] doorsteps' (SGP, 2012; UN, 2018). As an Island city that occupies on 700 square kilometres and 5.4 million people, it aims to ensure that integrating nature is a key priority (Subramanian, 2017). It also aims to set consistent standards for environmental sustainability across the entire city.

The $S G P$ is the first government document to formally highlight that planning and design needs to go beyond landscape architecture and parks planning and focus on built infrastructure as additional opportunities for landscaping and greening (SGP, 2012). It highlights political commitment to conserving and enriching nature by holding everyone equally accountable for achieving the goals of the SGP. Finally, the SGP also emphasizes the importance of replacing all-natural areas that get disturbed by local development, ensuring local biodiversity are sustained in the local system.

Singapore contains other policies and mechanisms that focus on extending both the cities and individual neighbourhoods' identity, out to the physical landscape and roadway that it pervades in order to create a 'seamless green mantle' and cohesive design across the city. These include the Streetscape Greenery Master Plan (SGMP) and the Green Mark Scheme (GMS). Each outline various planning and design guidelines and requirements for greening local buildings and increasingly assess the construction and environmental performance of various buildings with a focus on incorporating biophilic elements into its assessment process (Newman, 2015). Creative greening of the built environment has been more specifically advanced through policies like the Sky Green Incentive Scheme and the Landscape Replacement Policy that mandate that new buildings must, at minimum, replace the nature lost at ground level through their development (Meixian, 2017).

Finally, there are local initiatives that seek to extend local commitment to biophilic integration through public engagement. The city supports Horticulture Park, which is a gardening and lifestyle hub that sustains itself as a demonstration and greenery rich entity. It contains multiple varieties of green walls and roofs as an educational opportunity and tangible application for local planners, designers and builders. As an interactive park, it effectively shows local people that urban greenery is not as restrictive or complicated as it is often imagined to be. NParks has created a Center for Urban Greening and Ecology (CUGE) that promotes greenery in the city and trains landscape workers on new or developing green strategies. The intentional use of public demonstrations, education and engagement is continued through innovative developments showcased throughout the city. The Marina Bay Sands for example, is home to giant man-made trees referred to as "Gardens by the Bay" to highlight how local natural systems and cycles work in the city. These trees are intentionally large, dramatic and central to demonstrate how many different opportunities there are to integrate nature (Newman, 2012; Newman, 2017). 
The strategies, planning regulations and local initiatives in Singapore vary in scale and scope, successfully appealing to larger city initiatives that aim to enhance local greenery and sustainability and create a 'city in a garden' (Newman, 2012). They, along with countless other applications of biophilic design, have further contributed to increasing Singapore's green canopy cover by $20 \%$ despite a $70 \%$ increase in population between 1986-2007 (Newman, 2012). Singapore has recognized the potential for biophilic design to increase local biodiversity, reduce the urban heat island effect, enhance water management, reduce the built environments energy consumption and improve thermal comfort of the outdoors (Yok, Yeo, Xi \& Seong, 2009). As a result top-down efforts in combination with local scale efforts have successfully challenged planners, designers and developers to bring together lifestyle, function and design to create better places. In doing so they have been successful in creating a multiprong approach to city greening that goes beyond parks and landscaping to include and mandate biophilic design. They have demonstrated that with the right planning approach, community support, technical assistance, government incentives, political leadership and research and development, dense cities can still regenerate natural systems and effectively integrate greenery in their environments while supporting population growth. 


\subsubsection{United States}

Aqua Tower, Chicago
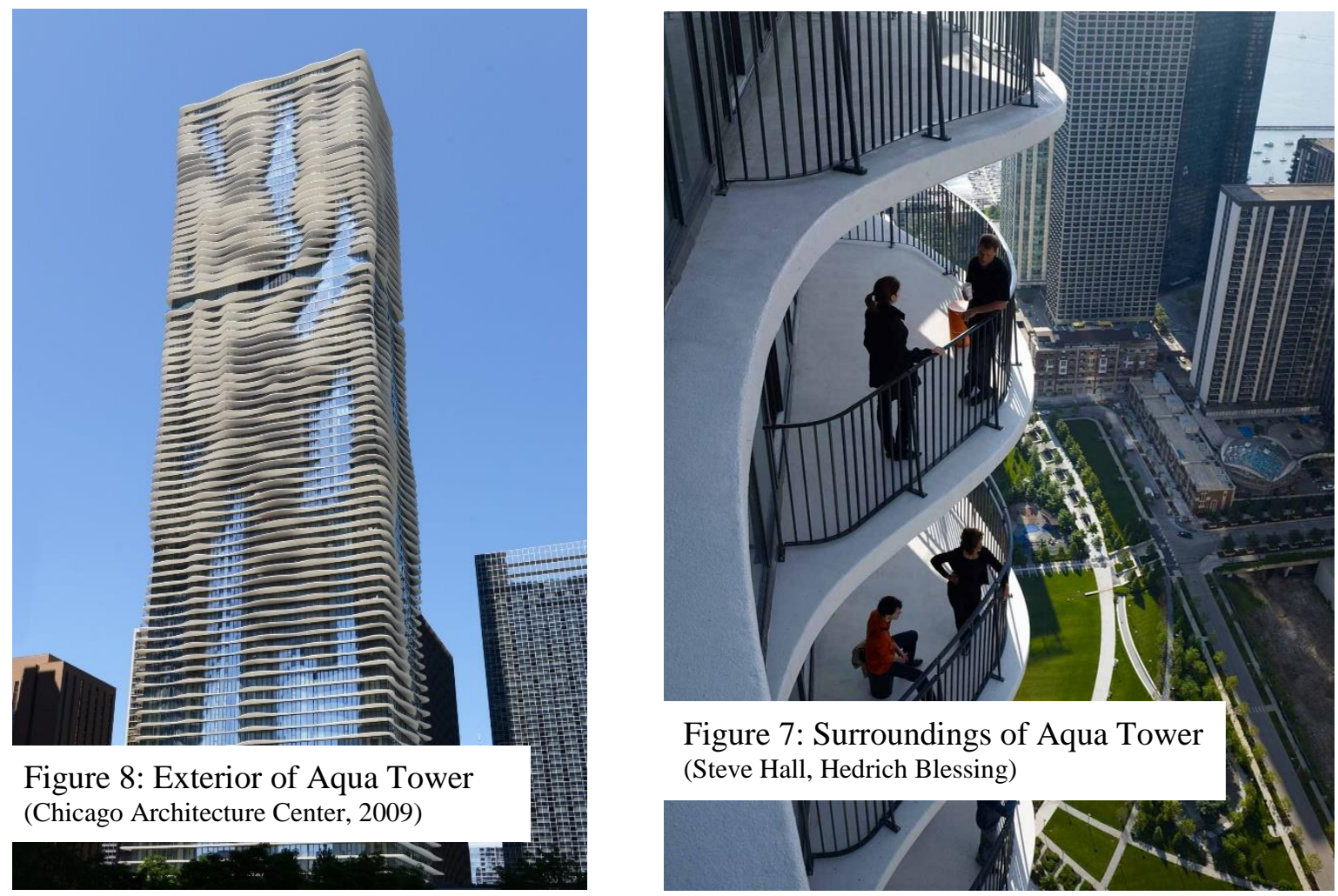

Aqua Tower is an 82-storey building located proximally to downtown Chicago. The building is mixeduse, containing a hotel, condominium suites and rental apartment units. The building, designed by architect Jeanne Gang, was designed to minimize fatal bird strikes that result from existing glass towers throughout the city (Gang, 2016). As a result, the architect intentionally created a wavy exterior to assist in the ability for birds to visually acknowledge the building.

The building also contains many green elements. The roof of the building contains a green roof while balconies are terraced with gardens and shrubs. Gang and her team also intentionally designed the terrace extensions to maximize natural solar shading of the building. In commonality with topographic features of the Great Lakes, slabs on the exterior of the building are comprised of striated limestone outcroppings (Gang, 2016). Finally, the building contains a water-efficient irrigation system and energy efficient lighting as a means to introduce further sustainable features on-site. 


\begin{tabular}{|c|c|c|}
\hline Pattern & Purpose & Utilized \\
\hline $\begin{array}{l}\text { Visual connection with } \\
\text { nature }\end{array}$ & $\begin{array}{l}\text { To stimulate pleasure, prolonged interest } \\
\text { and faster stress recovery by increasingly } \\
\text { grabbing one's attention, stimulating the } \\
\text { mind and creating a sense of respite and } \\
\text { ease. }\end{array}$ & $\begin{array}{l}\mathrm{X}-\text { Green roof and ample balconies, } \\
\text { terraced with gardens and shrubs. }\end{array}$ \\
\hline $\begin{array}{l}\text { Non-visual connection with } \\
\text { nature }\end{array}$ & $\begin{array}{l}\text { To introduce complex variable sounds } \\
\text { that are also familiar and comfortable } \\
\text { with the goal of contributing to mental } \\
\text { health, cognitive performance and more } \\
\text { targeted reductions to stress hormones. }\end{array}$ & \\
\hline Nonrhythmic sensory Stimuli & $\begin{array}{l}\text { Evolved from behaviour-based research, } \\
\text { with a goal of supporting relaxation, } \\
\text { improved attention and broader } \\
\text { physiological restoration. }\end{array}$ & \\
\hline $\begin{array}{l}\text { Thermal and airflow } \\
\text { variability }\end{array}$ & $\begin{array}{l}\text { To enhance worker comfort, well-being, } \\
\text { productivity and localized temporal and } \\
\text { spatial pleasure. By moderating sensory } \\
\text { variability this element aims to address } \\
\text { issues or boredom and passivity. }\end{array}$ & $\begin{array}{l}\mathrm{X}-\text { Solar heat gain from plants } \\
\text { alongside ample solar shading. } \\
\text { Striated limestone outcroppings, } \\
\text { varying access to wind, sun and } \\
\text { surrounding pressures. }\end{array}$ \\
\hline Presence of Water & $\begin{array}{l}\text { Evokes positive emotional responses and } \\
\text { visual preferences while contributing to } \\
\text { enhanced feelings of comfort, relaxation } \\
\text { and general emotional responses. }\end{array}$ & \\
\hline Dynamic and diffuse light & $\begin{array}{l}\text { Contributes to improved performance, } \\
\text { mood and well-being while also } \\
\text { improving body temperature, heart rate } \\
\text { and circadian functioning. }\end{array}$ & $\begin{array}{l}\mathrm{X}-\text { Large windows enabling access } \\
\text { to daylight, and direct sunlight at } \\
\text { multiple glares and distributions. } \\
\text { Terraced extension to maximize } \\
\text { natural solar shading. }\end{array}$ \\
\hline $\begin{array}{l}\text { Connection with natural } \\
\text { systems }\end{array}$ & $\begin{array}{l}\text { Suspected to enhance and improve health } \\
\text { responses with a particularly strong } \\
\text { temporal element. }\end{array}$ & \\
\hline $\begin{array}{l}\text { Biomorphic forms and } \\
\text { patterns }\end{array}$ & $\begin{array}{l}\text { To symbolically represent natural life } \\
\text { forms as a way to shift focus, and } \\
\text { enhance concentration, allowing users to } \\
\text { draw connections to nature. }\end{array}$ & $\begin{array}{l}\mathrm{X} \text { - Introduction of sun shading } \\
\text { elements, wavy exterior and } \\
\text { patterned facades. }\end{array}$ \\
\hline $\begin{array}{l}\text { Material connection with } \\
\text { nature }\end{array}$ & $\begin{array}{l}\text { Attempting to draw on improved } \\
\text { psychological responses to natural } \\
\text { materials and colors as a means to } \\
\text { integrate their role on enhanced cognitive } \\
\text { performance. }\end{array}$ & $\begin{array}{l}\mathrm{X}-\text { Patterned planes and accent } \\
\text { details to evoke positive emotions, } \\
\text { distinguish the building an enhance } \\
\text { visual quality. }\end{array}$ \\
\hline Complexity and order & $\begin{array}{l}\text { To strike a balance between boring and } \\
\text { overwhelming, to avoid added stress, } \\
\text { convey order and minimize physiological } \\
\text { tension. }\end{array}$ & $\begin{array}{l}\mathrm{X} \text { - Variety of natural and textured } \\
\text { wall coverings, and exposed } \\
\text { greening. }\end{array}$ \\
\hline Prospect & $\begin{array}{l}\text { Developed from psychology and } \\
\text { architectural analysis, the goal is to } \\
\text { promote reductions in stress, fatigue, } \\
\text { perceived vulnerability, while enhancing } \\
\text { comfort. }\end{array}$ & \\
\hline Refuge & $\begin{array}{l}\text { Provide users with accessible, protective } \\
\text { environments in support of individual } \\
\text { restoration and comfort, improved } \\
\text { concentration, attention and general } \\
\text { feelings of safety. }\end{array}$ & \\
\hline
\end{tabular}




\begin{tabular}{|l|l|l|}
\hline Mystery & $\begin{array}{l}\text { Intended to heighten individual curiosity, } \\
\text { increase interest and local preference } \\
\text { while providing pleasure responses to } \\
\text { anticipatory situations. }\end{array}$ & \\
\hline Risk/Peril & $\begin{array}{l}\text { Providing and awareness of controllable } \\
\text { risk, to introduce positive encounters that } \\
\text { then result in strong dopamine and/or } \\
\text { pleasure responses to surrounding } \\
\text { environments. }\end{array}$ & \\
\hline
\end{tabular}

\section{Context for Biophilic Design in Chicago}

The integration and growth of biophilic design in Chicago was greatly influenced by local political advocacy, and their ability to gain support for programs that center on increasing nature in the city. The former Chicago Mayor Richard Daley was committed to urban greening in Chicago and made it a 22-year focus of the city. With this focus came countless plans, policies and programs orchestrated around encouraging the use of nature in various components of the city's urban design. Chicago, for example, contains over 600 green roofs that spread roughly 5 million square feet, over 500,000 additional trees and 110 miles of landscapes median strips (Newman, 2012).

Commitment to biophilia and biophilic design was exhibited back in 1990s through the establishment of a tree-planting campaign and a Landscape Ordinance. The ordinance required developers to integrate green elements in their projects, with the goal of beautifying the city. Chicago also launched the Cityspace Plan (1997) that outlined opportunities for green space and green integration within the city. The city has more specifically developed a plan entitled: Adding Urban Green to Urban Design Plan to identify strategies that effectively marry compact, mixed-use, dense urban design with tools to mitigate the negative environmental impacts of this urban form (Newman, 2012). The goal is to guide development through the presentation of alternatives, while simultaneously minimizing opportunities for excuses.

Larger policy goals have been outlined through the Chicago Water Agenda and the city's agreement to become a member of the Chicago Climate exchange. With goals of reducing local reliance on sewer systems and greenhouse gas emitting infrastructure these commitments have indirectly increased the need for local greening and green infrastructure.

Chicago also promotes the importance of local greening through educational and demonstrative developments in the city. The city successfully funded and developed the worlds first municipal LEED Platinum building known as the Chicago Center for Green Technology (Newman, 2012). This facility effectively communicates the city's commitment to greening and provides a free design educational facility for other buildings to imitate. With a similar approach, the city has launched the Chicago 
Conservation Corps (2006) to train members of the community to run and initiate local projects the intentionally introduce nature into the city in innovative ways (CCC, 2006; Newman, 2012).

Finally, Chicago employs financial instruments to encourage green elements and reduce potential obstacles. The city offers grants to support green roof construction through the Green Roofs Grant program, they aim to expedite building permit applications with green elements through the Green Permit Program and offer density bonusing to developments with green roofs, allowing them to increase the number of dwellings on their site (GFC, 2012). They also use tax increment financing to leverage the future revenue from increased property taxes in the city. Many of these instruments are cost-neutral or of minimal cost to the city but aim to promote greening, help overcome potential costs and burdens and further represent government commitment.

A key to success in Chicago has been collaboration, particularly between government departments. Most policies and established programs including; the Adding Green to Urban Design Plan, the Chicago CitySpace Plan, and the Chicago Climate Change Action Plan span varying government departments to ensure consistency in approach and standards across the city (City of Chicago, 2008; Newman, 2012). The planning and development of these plans and policies have also relied on extensive community consultation, such that they effectively target community needs, groups and can then attain in-kind support through private-public partnerships. A previous employee of the Department of the Environment, Aaron Durnbaugh, summarized this approach as a 3-pronged approach: the 'tambourine' (demonstration, quantification and education), the 'carrot' (incentives) and the 'stick' (regulation)' (Durnbaugh, 2012). It has credited with helping develop support, engagement and application of advanced biophilia in the city. 


\subsubsection{Australia}

One Central Park, Sydney
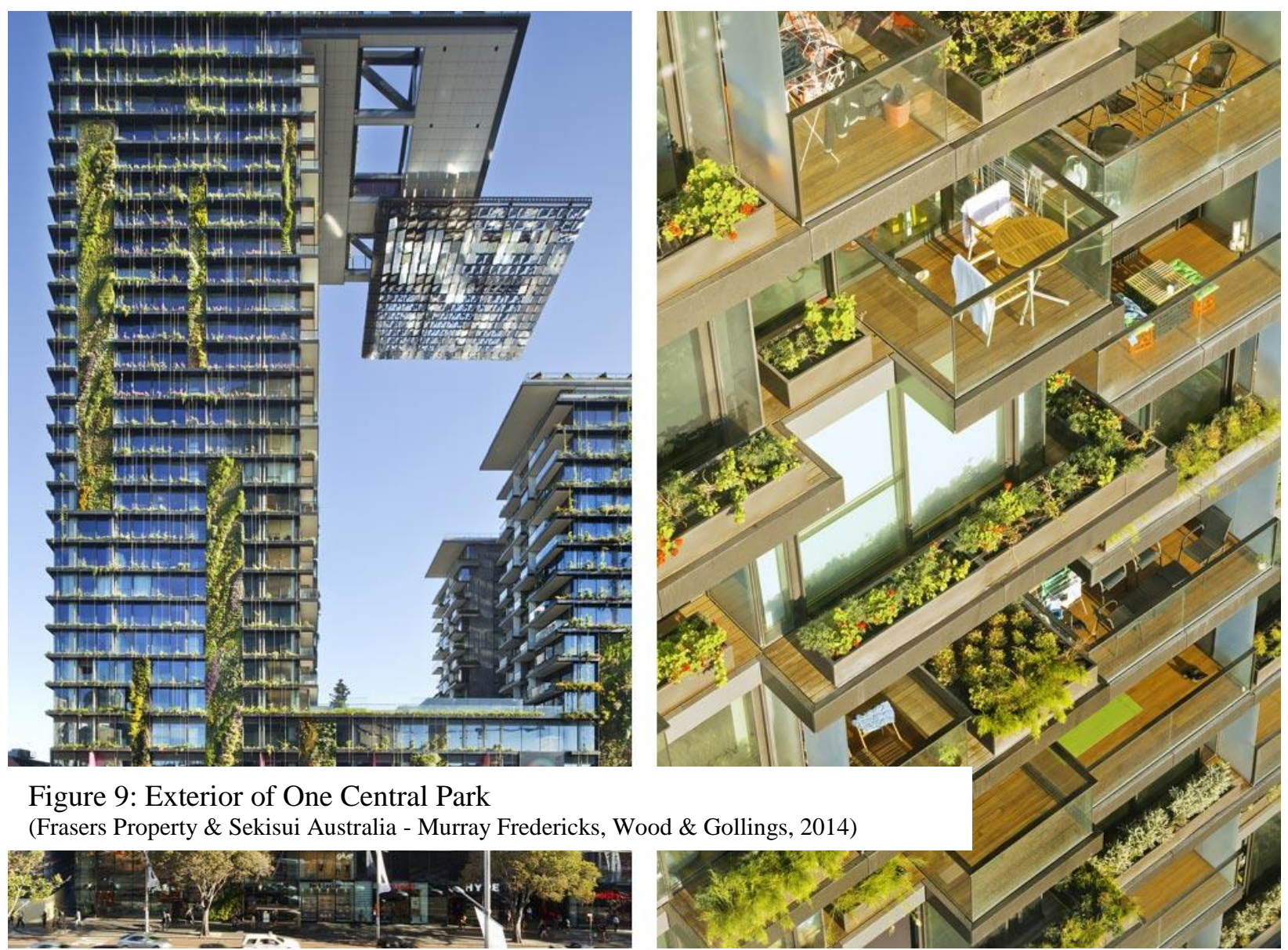

Figure 9: Exterior of One Central Park

(Frasers Property \& Sekisui Australia - Murray Fredericks, Wood \& Gollings, 2014)

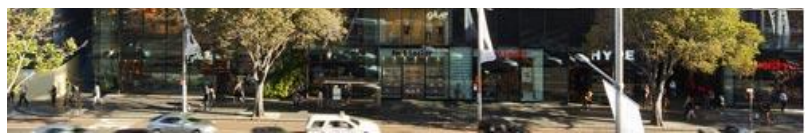

One Central Park is in the center of Sydney, Australia. The new 34-storey residential building recognized the opportunity to create a visible and powerful green statement while responding to growing residential demand in the city. As such, the master plan for the building employed a broad approach to carbon conscious design using two innovative technologies; hydroponics and heliostats. These plans follow but also aim to exceed planning targets set out by the Green Star Rating System and Green Building Council of Australia (GBCA) (Nouvel, 2014).

The exterior of the building is covered in a variety of plant life by way of green walls, climbing vegetation and continuous planter bands (CTBUH, 2019). These plants are randomly scattered across the facades such that each resident can benefit from their own balcony, private garden and collective urban garden provided by the building. They additionally help support and redirect sunlight for natural heating and lighting while providing organic shading in the area, reducing the thermal impact of the building by 
30\% (Nouvel, 2014). The plants are irrigated with recycled water with the opportunity to custom tailor their needs depending on their type and structural positioning. Beyond the technicalities of these plants, each assist in offering enjoyment and respite for residents and the public. The building also contains a park at its base to strengthen the buildings community integration and assist in greening the city from floor to sky.

The design of this building was based on a desire to contribute to Sydney's goal of reducing their carbon footprint. Relative to comparable high-rise buildings in the area One Central Park has been successful in reducing its energy consumption by $26 \%$ alongside the $30 \%$ reduction in its thermal impact (CTBUH, 2019). As a result, the building has been classified as a "State Significant Development" under approval by the Minister of Planning, acting as a public quality benchmark for the rest of the city.

\begin{tabular}{|c|c|c|}
\hline Pattern & Purpose & Utilized \\
\hline $\begin{array}{l}\text { Visual connection with } \\
\text { nature }\end{array}$ & $\begin{array}{l}\text { To stimulate pleasure, prolonged interest } \\
\text { and faster stress recovery by increasingly } \\
\text { grabbing one's attention, stimulating the } \\
\text { mind and creating a sense of respite and } \\
\text { ease. }\end{array}$ & $\begin{array}{l}\mathrm{X}-\text { Green walls, climbing } \\
\text { vegetation and continuous planter } \\
\text { bands. }\end{array}$ \\
\hline $\begin{array}{l}\text { Non-visual connection with } \\
\text { nature }\end{array}$ & $\begin{array}{l}\text { To introduce complex variable sounds } \\
\text { that are also familiar and comfortable } \\
\text { with the goal of contributing to mental } \\
\text { health, cognitive performance and more } \\
\text { targeted reductions to stress hormones. }\end{array}$ & \\
\hline Nonrhythmic sensory Stimuli & $\begin{array}{l}\text { Evolved from behaviour-based research, } \\
\text { with a goal of supporting relaxation, } \\
\text { improved attention and broader } \\
\text { physiological restoration. }\end{array}$ & $\begin{array}{l}\mathrm{X}-\text { Rustling of plants, lower } \\
\text { movement of water, reflections off } \\
\text { surrounding water. }\end{array}$ \\
\hline $\begin{array}{l}\text { Thermal and airflow } \\
\text { variability }\end{array}$ & $\begin{array}{l}\text { To enhance worker comfort, well-being, } \\
\text { productivity and localized temporal and } \\
\text { spatial pleasure. By moderating sensory } \\
\text { variability this element aims to address } \\
\text { issues or boredom and passivity. }\end{array}$ & $\begin{array}{l}\mathrm{X} \text { - Plants help support and redirect } \\
\text { sunlight for natural heating and } \\
\text { lighting, while providing organic } \\
\text { shading in the area. }\end{array}$ \\
\hline Presence of Water & $\begin{array}{l}\text { Evokes positive emotional responses and } \\
\text { visual preferences while contributing to } \\
\text { enhanced feelings of comfort, relaxation } \\
\text { and general emotional responses. }\end{array}$ & $\begin{array}{l}\mathrm{X} \text { - Irrigation is fostered through } \\
\text { recycled water, creating water flows } \\
\text { and noises heard at various points of } \\
\text { the building. }\end{array}$ \\
\hline Dynamic and diffuse light & $\begin{array}{l}\text { Contributes to improved performance, } \\
\text { mood and well-being while also } \\
\text { improving body temperature, heart rate } \\
\text { and circadian functioning. }\end{array}$ & $\begin{array}{l}\mathrm{X} \text { - Large windows enabling access } \\
\text { to daylight, and direct sunlight at } \\
\text { multiple glares and distributions. }\end{array}$ \\
\hline $\begin{array}{l}\text { Connection with natural } \\
\text { systems }\end{array}$ & $\begin{array}{l}\text { Suspected to enhance and improve health } \\
\text { responses with a particularly strong } \\
\text { temporal element. }\end{array}$ & $\begin{array}{l}\mathrm{X}-\text { Enhanced exposure to } \\
\text { surrounding plants and variations } \\
\text { imposed by weather changes. }\end{array}$ \\
\hline $\begin{array}{l}\text { Biomorphic forms and } \\
\text { patterns }\end{array}$ & $\begin{array}{l}\text { To symbolically represent natural life } \\
\text { forms as a way to shift focus, and } \\
\text { enhance concentration, allowing users to } \\
\text { draw connections to nature. }\end{array}$ & \\
\hline
\end{tabular}




\begin{tabular}{|c|c|c|}
\hline $\begin{array}{l}\text { Material connection with } \\
\text { nature }\end{array}$ & $\begin{array}{l}\text { Attempting to draw on improved } \\
\text { psychological responses to natural } \\
\text { materials and colors as a means to } \\
\text { integrate their role on enhanced cognitive } \\
\text { performance. }\end{array}$ & \\
\hline Complexity and order & $\begin{array}{l}\text { To strike a balance between boring and } \\
\text { overwhelming, to avoid added stress, } \\
\text { convey order and minimize physiological } \\
\text { tension. }\end{array}$ & \\
\hline Prospect & $\begin{array}{l}\text { Developed from psychology and } \\
\text { architectural analysis, the goal is to } \\
\text { promote reductions in stress, fatigue, } \\
\text { perceived vulnerability, while enhancing } \\
\text { comfort. }\end{array}$ & $\begin{array}{l}\mathrm{X}-\text { Enhanced access to balconies } \\
\text { and included greenings. Elevated } \\
\text { open floor plans designed to increase } \\
\text { exposure and views. }\end{array}$ \\
\hline Refuge & $\begin{array}{l}\text { Provide users with accessible, protective } \\
\text { environments in support of individual } \\
\text { restoration and comfort, improved } \\
\text { concentration, attention and general } \\
\text { feelings of safety. }\end{array}$ & $\begin{array}{l}\mathrm{X} \text { - Plants offer enjoyment and areas } \\
\text { of respite for residents of the } \\
\text { building because of their magnitude } \\
\text { and positioning. }\end{array}$ \\
\hline Mystery & $\begin{array}{l}\text { Intended to heighten individual curiosity, } \\
\text { increase interest and local preference } \\
\text { while providing pleasure responses to } \\
\text { anticipatory situations. }\end{array}$ & $\begin{array}{l}X-\text { Increased movement, sounds } \\
\text { and natural scents provided on and } \\
\text { surrounding the site. Windows help } \\
\text { reveal and expose people to distinct } \\
\text { features. }\end{array}$ \\
\hline Risk/Peril & $\begin{array}{l}\text { Providing and awareness of controllable } \\
\text { risk, to introduce positive encounters that } \\
\text { then result in strong dopamine and/or } \\
\text { pleasure responses to surrounding } \\
\text { environments. }\end{array}$ & $\begin{array}{l}\mathrm{X} \text { - Broad approach to carbon } \\
\text { conscious design using hydroponics } \\
\text { and heliostats introduces innovation } \\
\text { and unique elements to the structure. }\end{array}$ \\
\hline
\end{tabular}

Melbourne Metro, Melbourne

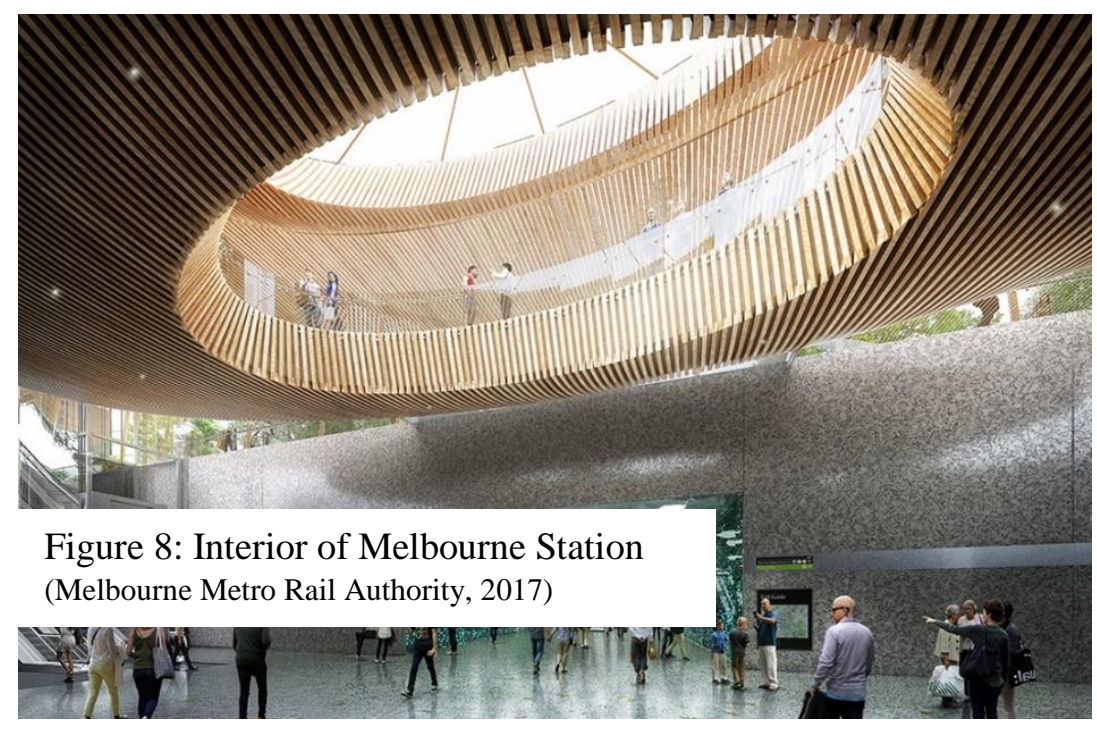

Melbourne Metro is undergoing development of five new railway stations. The aim is for these stations to be the first public infrastructure developments in Australia to incorporate biophilic design and look beyond standard practice (ADR, 2017) as highlighted by Dr Phillip Roös (2017) from Deakin University: 
“This isn't just about low-impact features like green power or water recycling, it is also recognising that

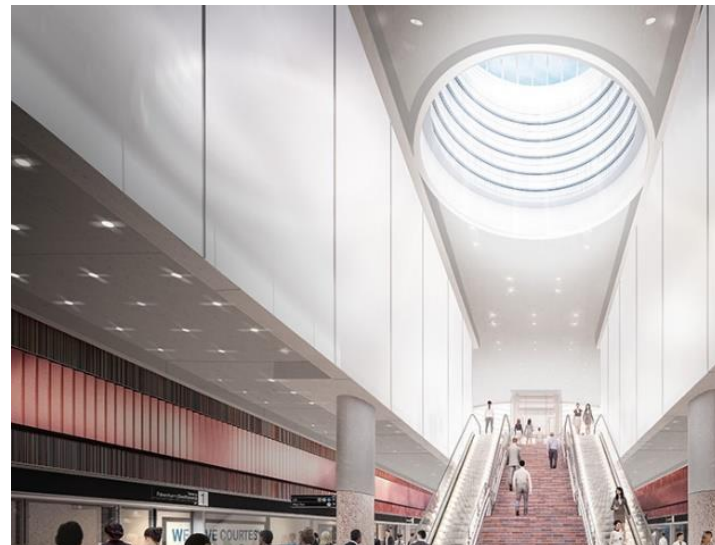

Figure 9: Interior of Melbourne Station (Melbourne Metro Rail Authority, 2017)

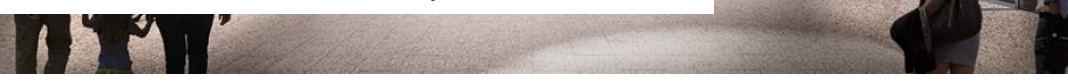
humans are drawn to the patterns inherent in living things, so if we can create something that follows these rules of nature, humans will benefit as well as the planet."

The vision for Melbourne Metro is underpinned by a targeted Sustainability Strategy, a Living Infrastructure Plan, an Urban Design Strategy and a Creative Strategy. Each were developed through ongoing collaboration between many university researchers and the Melbourne Rail Authority, with a focus on creating and incorporating 15 distinct patters of biophilic design (Downtown et al., 2017). These patterns, outlined in the Creating Healthy Places Report, are heavily guided by Terrapin Bright Green's 14 patterns of Biophilic Design but are uniquely tailored to the aspirations and motivations of Melbourne's residents, designers and commuters (Downtown et al., 2017). They include the deliberate incorporation of components like the presence of water, dynamic light, incorporation of places of refuge and mystery and a more deliberate, ongoing visual connection to nature.

The stations are dominated by natural light, open spaces, terraced seating and sweeping arches, accessible by pedestrians and cyclists. The material palettes of each station have been chosen to reflect the character of the area and in some cases, the area's industrial history through use of bluestone, brick, timer, steel and glass. Vast planting is planned for station entrances and surroundings with the intent of helping the city combat the urban heat island effect as outlined in the cities Urban Forest Strategy and increasing biodiversity and habitat for local flora and fauna.

Hoardings or tunnel areas for the stations are proposed to have living green walls as a way to enhance the visual appeal of the area while reducing heat, contributing to noise reduction and absorbing dust and other airborne contaminants (Aliento, 2017). The design finally aims to enhance water sensitivity by using permeable paving, raingardens and planting to manage storm water, provide flood prevention and bring the stations to life.

The Melbourne Metro is using this development opportunity to push the local design envelope and create an international benchmark for the incorporation and application of biophilic design. The Metro intends to 
acknowledge the beneficial qualities of biophilia and their importance in creating liveable cities that continue to urbanize. In doing so, the Metro is also supportive and in line with the cities goal of maintaining itself as an internationally recognized "ecocity", its core strategic aims of Melbourne 2030 and the Melbourne City Council Plan 2013-2017 (Downtown et al., 2017).

\begin{tabular}{|c|c|c|}
\hline Pattern & Purpose & Utilized \\
\hline $\begin{array}{l}\text { Visual connection with } \\
\text { nature }\end{array}$ & $\begin{array}{l}\text { To stimulate pleasure, prolonged interest } \\
\text { and faster stress recovery by increasingly } \\
\text { grabbing one's attention, stimulating the } \\
\text { mind and creating a sense of respite and } \\
\text { ease. }\end{array}$ & $\begin{array}{l}\mathrm{X} \text { - Living green walls, hanging } \\
\text { plants and vast planting dispersed } \\
\text { inside and outside. }\end{array}$ \\
\hline $\begin{array}{l}\text { Non-visual connection with } \\
\text { nature }\end{array}$ & $\begin{array}{l}\text { To introduce complex variable sounds } \\
\text { that are also familiar and comfortable } \\
\text { with the goal of contributing to mental } \\
\text { health, cognitive performance and more } \\
\text { targeted reductions to stress hormones. }\end{array}$ & $\begin{array}{l}\mathrm{X} \text { - Provision of green space and } \\
\text { planting alongside varying materials } \\
\text { advances fragrant smells, presence } \\
\text { of warm/cool surfaces, natural } \\
\text { ventilation opportunities and sound } \\
\text { of water, air and rustling plants. }\end{array}$ \\
\hline Nonrhythmic sensory Stimuli & $\begin{array}{l}\text { Evolved from behaviour-based research, } \\
\text { with a goal of supporting relaxation, } \\
\text { improved attention and broader } \\
\text { physiological restoration. }\end{array}$ & $\begin{array}{l}\mathrm{X}-\text { Rustling of plants, water } \\
\text { movement and reflections, captured } \\
\text { and reused rainwater runoff. }\end{array}$ \\
\hline $\begin{array}{l}\text { Thermal and airflow } \\
\text { variability }\end{array}$ & $\begin{array}{l}\text { To enhance worker comfort, well-being, } \\
\text { productivity and localized temporal and } \\
\text { spatial pleasure. By moderating sensory } \\
\text { variability this element aims to address } \\
\text { issues or boredom and passivity. }\end{array}$ & $\begin{array}{l}\mathrm{X}-\text { Solar heat gain from plants, } \\
\text { varying airflow through tunnels, } \\
\text { plant adaptation and use. }\end{array}$ \\
\hline Presence of Water & $\begin{array}{l}\text { Evokes positive emotional responses and } \\
\text { visual preferences while contributing to } \\
\text { enhanced feelings of comfort, relaxation } \\
\text { and general emotional responses. }\end{array}$ & $\begin{array}{l}\mathrm{X}-\text { Integration of permeable paving, } \\
\text { raingardens and planting to enhance } \\
\text { water retention, integration and } \\
\text { management. }\end{array}$ \\
\hline Dynamic and diffuse light & $\begin{array}{l}\text { Contributes to improved performance, } \\
\text { mood and well-being while also } \\
\text { improving body temperature, heart rate } \\
\text { and circadian functioning. }\end{array}$ & $\begin{array}{l}\mathrm{X} \text { - Large windows enabling access } \\
\text { to daylight, and direct sunlight at } \\
\text { multiple glares and distributions. }\end{array}$ \\
\hline $\begin{array}{l}\text { Connection with natural } \\
\text { systems }\end{array}$ & $\begin{array}{l}\text { Suspected to enhance and improve health } \\
\text { responses with a particularly strong } \\
\text { temporal element. }\end{array}$ & $\begin{array}{l}\mathrm{X} \text { - Living walls among other } \\
\text { features help reduce heat, reduce } \\
\text { noise, and absorb dust and other } \\
\text { airborne contaminants. }\end{array}$ \\
\hline $\begin{array}{l}\text { Biomorphic forms and } \\
\text { patterns }\end{array}$ & $\begin{array}{l}\text { To symbolically represent natural life } \\
\text { forms as a way to shift focus, and } \\
\text { enhance concentration, allowing users to } \\
\text { draw connections to nature. }\end{array}$ & $\begin{array}{l}\mathrm{X}-\text { Introduction of sun shading } \\
\text { elements, open spaces, terraced } \\
\text { seating and sweeping arches. }\end{array}$ \\
\hline $\begin{array}{l}\text { Material connection with } \\
\text { nature }\end{array}$ & $\begin{array}{l}\text { Attempting to draw on improved } \\
\text { psychological responses to natural } \\
\text { materials and colors as a means to } \\
\text { integrate their role on enhanced cognitive } \\
\text { performance. }\end{array}$ & $\begin{array}{l}\mathrm{X}-\text { Patterned planes and accent } \\
\text { details to evoke positive emotions. } \\
\text { Unique materials and patterns } \\
\text { including bluestone, brick, timer, } \\
\text { steel and glass throughout. }\end{array}$ \\
\hline Complexity and order & $\begin{array}{l}\text { To strike a balance between boring and } \\
\text { overwhelming, to avoid added stress, } \\
\text { convey order and minimize physiological } \\
\text { tension. }\end{array}$ & $\begin{array}{l}\mathrm{X}-\text { Variety of natural and textured } \\
\text { wall coverings, exposed greening, } \\
\text { landscaped and planned floor levels } \\
\text { and pedestrian routes. }\end{array}$ \\
\hline
\end{tabular}




\begin{tabular}{|l|l|l|}
\hline Prospect & $\begin{array}{l}\text { Developed from psychology and } \\
\text { architectural analysis, the goal is to } \\
\text { promote reductions in stress, fatigue, } \\
\text { perceived vulnerability, while enhancing } \\
\text { comfort. }\end{array}$ & $\begin{array}{l}\text { X- Distant and long focal lengths } \\
\text { creating clear pathways and } \\
\text { navigation through the space. Open } \\
\text { floor plans and scattered or elevated } \\
\text { planes scattered throughout, creating } \\
\text { distinct, unique and variable views. }\end{array}$ \\
\hline Refuge & $\begin{array}{l}\text { Provide users with accessible, protective } \\
\text { environments in support of individual } \\
\text { restoration and comfort, improved } \\
\text { concentration, attention and general } \\
\text { feelings of safety. }\end{array}$ & $\begin{array}{l}\text { X- Hoarding, tunnels and small } \\
\text { protection elements are integrated } \\
\text { within and throughout stations. }\end{array}$ \\
\hline Mystery & $\begin{array}{l}\text { Intended to heighten individual curiosity, } \\
\text { increase interest and local preference } \\
\text { while providing pleasure responses to } \\
\text { anticipatory situations. }\end{array}$ & $\begin{array}{l}\text { X-Increased movement, sounds } \\
\text { and natural scents provided on and } \\
\text { surrounding the site. Windows help } \\
\text { reveal and expose people to distinct } \\
\text { features while greening is carried } \\
\text { right through to the interior. }\end{array}$ \\
\hline Risk/Peril & $\begin{array}{l}\text { Providing and awareness of controllable } \\
\text { risk, to introduce positive encounters that } \\
\text { then result in strong dopamine and/or } \\
\text { pleasure responses to surrounding } \\
\text { environments. }\end{array}$ & $\begin{array}{l}\text { X-Varying heights, facades, and } \\
\text { floor planes that create an } \\
\text { immersive, uncontrollable } \\
\text { experience inside and out. }\end{array}$ \\
\hline
\end{tabular}

Context for Biophilic Design in Australia

The integration and development of biophilic design in Australia is more recent, relative to some of the other cases discussed. Much of this trend is reflected in recent policy and political decisions that aim to improve city conservation and green efforts. One document includes the Australia's Biodiversity

Conservation Strategy 2010-2030. This document provides a national framework and targets that aim to increase the number of local people, public and private entities participating in conservation activities by $25 \%$. In consideration that $80 \%$ of Australian people live in cities, the goal is to educate and engage citizens on the importance of preserving and restoring habitat and green space. It additionally aims to remove the notion that biodiversity conservation is something that only occurs outside cities.

At a municipal level, Australian cities have recently outlined the importance of city greening through strategic action plans. Melbourne has introduced a 4-year plan entitled the Green Our City Strategic Action Plan that aims to specifically improve the quantity and quality of vertical greening and green roofs. Planning permits and requirements are outlined by way of the Melbourne Planning Scheme to minimize barriers to use and development. Sydney has introduced the Environmental Action Strategy and Action Plan, with the goal of reducing carbon pollution and boosting renewable energy, growing their urban canopy and raising environmental standards of the built environment (City of Sydney, 2017). The documents of each municipality centers on supporting municipal efforts to create more livable, resilient cities in the face of climate change. 
In 2017, Melbourne also endorsed a Nature in the City Strategy, which centers on the opportunity to "actively foster connections between people, plants, animals and the landscape" to ensure the community is "connected to nature and place, is active in protecting and enhancing biodiversity, and enjoys the associated benefits to health and wellbeing" (City of Melbourne, 2017). With a series of three goals and six priority objectives to guide local planning, development and management, these documents suggest the potential of biophilic design to appeal to larger planning and policy objectives. Melbourne further supports this through the development of a Greening Your Building Toolkit that contains upwards of 70 management, design, planning and refurbishment objectives for existing and new builds. The goal was to create a cohesive document to direct the development of green buildings, present accessible environmental opportunities and help inform people about simple, valuable changes they can make to enhance buildings environmental performance (City of Melbourne, 2007).

From a localized approach, some cities like Melbourne, have launched specific initiatives to encourage the integration of biophilic design. The Living Future Institute (ILFI) for example has launched an initiative to provide education and knowledge sharing opportunities around biophilic design. The goal is to eventually reconnect people to nature by way of inspiring and educating local professionals in the community and specifically those involved in shaping the built environment (Living Future Institute Australia, 2017). The City is also supported by local efforts and practices such as the certification process, the Living Building Challenge. Now considered the built environments most rigorous performance standard, this certification process recognizes developments that operate as clearly and efficiently as nature's architecture (Living Future Institute Australia, 2017). Developments seeking to be recognized by the Living Building Challenge not only have to be zero net energy, water and waste over 12 months of operation, but they are also required to use biophilic design as a mechanism to influence and promote larger scale integration and interest in the city (Living Future Institute Australia, 2017).

\subsection{Discussion}

The exploration of these cases has identified 6 key findings highlighted below.

1. Biophilic design can and is adopted at various scales and intensities that ultimately influences the number of patterns of biophilic design adopted and effectively integrated.

2. Planning, policy and incentives are a key way to support and promote the development of biophilic design.

3. The integration of biophilic design is guided by commitment, knowledge, interest and expertise of local developers, planners and designers.

4. The integration of biophilia and biophilic design is expedited by a supportive political agenda and government commitment.

5. There are many tools and strategies to encourage implementation that rely on the local and regional context of a place. Rather, there is no single approach to promoting integration. 
6. Networks, designations and certification systems, like The Biophilic Cities Network, help support the adoption and integration of biophilic design by enhancing recognition.

Each of these findings came through the analysis of the cases studies above. Below, each of these findings are expanded upon.

\section{Biophilic Design Can and Is Employed at Different Scales}

The integration of biophilic design evidently amounts at different scales and intensities in different places. Different cities, and even places within the same city, uniquely apply biophilic design through different patterns and multi-functional features.

Some places clearly employ components of biophilic design as a means to enhance, contribute and appeal to larger sustainability initiatives of their region. These buildings, as evidenced by the Chicago Aqua Tower and 158 Cecil Street in Singapore for example, tend to comprise more extensive and green outdoor living environments with a goal of contributing to environmental surroundings through improved air quality, a reduced carbon footprint, and reductions in water and energy efficiency. As a result, key biophilic design features in these buildings and places include elements like sky gardens, green roofs, plant-filled balconies, climbing vegetation and green walls. They focus on effectively animating spaces and places and increasing local greenery but less consistently employ the 14 Patterns of Biophilic Design, especially components of complexity and order, prospect, refuge, mystery, and risk and peril. Much of this trend can be attested to their more advanced stages of development where structural or physical adjustments are less possible. Additionally, and uniquely, the use of biophilic design in these buildings is typically not for the purpose of offering mental, physical and psychological benefits but instead focuses strictly on environmental benefits.

Conversely, other cases clearly highlighted that biophilic design is often integrated at a larger scale with the goal of similarly enhancing site sustainability and larger environmental objectives of a place while more deliberately including the 14 Patterns of Biophilic Design. These spaces tend to have a more direct goal to create spaces that offer other related benefits for society, economics and public health as identified in the literature review. As such, their designs tend to involve similar exterior green elements but additionally introduce more innovative building envelopes that intentionally reflect natures elements and forms such as sweeping arches, hoardings, water elements, distinct and natural materials and diffuse lighting. In doing so, these designs such as a Khoo Teck Puat Hospital and the Melbourne Metro extension more explicitly mimic the intent and patterns of biophilic design, contribute and enhance local nature, and simultaneously aim to provide more direct benefits to human health and well-being in their city's. 
Both design approaches, represent important ways to bring nature and its inherent benefits into urban realms at small and large scales. Each are successful in contributing to local environmental efforts, primarily at the neighbourhood level, and undoubtedly make a huge difference to local greening efforts, counteracting reductions in flora and fauna and mitigating concerns of flooding. While larger efforts are unique in their capacities to more specifically contribute to human health, well-being and economics alongside their efforts in developing a more environmentally conscious built environment.

\section{Financial Supports Help Advance Integration of Biophilic Design}

Another key finding from the cases was that public policy, which incorporates financial subsidies and incentives, are key to bolstering private inventiveness and willingness. This idea came through examples like Singapore's NParks financial subsidies for green roofs and their Sky Green Incentive Scheme, alongside the Chicago Green Roofs Grant Program. Each demonstrate how important engaging the private sector can be in biophilic design and planning.

\section{Integration is Influenced by the Commitment, Interest and Expertise of Local Professionals}

The cases identify that city planning and policy can successfully incorporate a biophilic lens and take a more holistic approach to planning and achieving more abundant nature in cities. However, the capacity of these plans to have impact is tied to the interest and understanding of other professionals including architects, designers, engineers, politicians and scientists. Without the direct, active involvement of these groups it is hard to see how the integration of biophilic design would even be possible. The well-known architect Bjarke Ingels (2018) for example, is devoted to creating and imagining buildings that respond to the local environment and climate (Harlow, 2019). He additionally carries the technical expertise and team to effectively and properly integrate and use biophilic design. Each of the cases discussed were supported by unique and talented individuals who understand biophilic design as a concept and were experienced and educated in making it a reality of their designs.

\section{Targeted Tools and Strategies are Valuable in Promoting Integration}

The cases additionally demonstrated the significant role that local planning and policies have in enriching the quality and type of biophilia in the built environment. They have a more specific role in shaping local land use and development requirements to ensure that biophilic design and the ultimate enrichment of biophilia in urban areas is even possible. This approach can be seen in many cases beyond the ones discussed above. For example, Berlin has enriched the presence of biophilia and biophilic design in their urban core through the introduction of the Biotope Area Factor. This Factor requires applicable new residential and commercial structures to have a respective, $60 \%$ and $30 \%$ ecologically effective area, 
otherwise known as area that has positive effect on the ecosystem, on site (Newman, 2012). This urban development policy is intentionally flexible to ensure developers and planners have agency in how they achieve this outcome, but concurrently aims to set clear and consistent local targets that will help sustain city green while reducing ecological impacts of the inner-city area (SDUDE, 2018). Interestingly, these local planning policies discussed are not explicitly stating or requiring decision makers to embed biophilic design. They instead use requirements, thresholds and targets to make biophilic design; more specifically, green roofs and vertical greening, more necessary and viable.

\section{Political Support is Paramount for Success}

In many cases, strong political support has been fundamental to success as it helps gives credibility to the biophilic framework while providing important advocacy efforts to ensure things get done. Progressive, forward thinking and dedicated leadership has proven essential in getting people on board and generating a positive impact. Commitment from political leaders in Chicago and Singapore, for example, were paramount in shifting city focus and educating local people about need. They also each highlight the immense value of placing nature at the center of local planning and design. Especially promising, is Singapore's development and mandate to become a 'City in a Garden', solidifying the idea that nature is not something separate but something that should be explored by all residents everyday. Leadership was not only key in demonstrating that biophilic design is a mechanism to enhance the integration of nature in urban environments but was also essential in developing a policy framework that makes integration possible and feasible.

\section{Networks, Designations and Certification Systems, Help Gain Support for Integration}

Finally, it was noted that planning regulations and policy do not always directly amount to the intentional incorporation and use of biophilic design at large scales. Planning regulations and policy explored in these cases tend to support the use of biophilic design, increase the financial benefit of doing so, and emphasize the social value of integration, but do not directly target or direct use. Actual application tends to be fundamentally guided by two things. The first being commitment and innovation of individual and local developers and planners. In the cases explored, the developers, planners and firms behind the project comprise individuals who are keen to design and create places that defy traditional conventions and create bold sustainable developments. They, in other words, have the unique capacity, skills and interest to implement biophilic design.

The second key factor influencing the integration of biophilic design stems from a local desire to appeal to and fit in with larger networks and entities. Singapore's large-scale adoption of biophilic design for example can be attributed to its larger goal and recognition as a biophilic city. A biophilic city as defined 
by Timothy Beatley (2010) is a "city that puts nature first in its design, planning, and management; it recognizes the essential need for daily human contact with nature as well as the many environmental and economic values provided by nature and natural systems".

As a partner or member city, biophilic cities become recognized as more vibrant, nature filled places, are exposed to formal network events, research and urban design and planning strategies, and finally become recognized as leaders in sustainable urbanism (BCN, 2017). In consideration that being a biophilic city involves green urbanism, green infrastructure and biophilic design, places like Singapore have gradually and intentionally changed municipal planning and local urban design polices to ensure the city continually provides abundant nature near local urbanites, as outlined by the biophilic cities network (Beatley, 2012).

At a smaller but similar scale, some cities have achieved greater application of biophilic design through localized networks and certifications processes such as the Living Standards Institute in Australia. This network similarly seeks to formalize the practice of biophilic design to heighten its appeals and enhance its credibility. It also gives planners, developers and designers the opportunity to distinguish themselves and their work from others in the field.

These 6 findings identify current trends in the use and application of biophilic design around the world. However, they also begin to identify potential obstacles to local application. A lack of developer and planner knowledge, awareness and expertise may impede local development of biophilic design, while a lack of access to or integration in network opportunities may have the same impact. Furthermore, if planning and policy initiatives do not currently provide adequate incentives, targeted policy and guiding strategies to encourage development this may be an additional obstacle to use. This concept extends further to the role of politics. If local politicians; and their respective political agendas, planning and policy documents, do not demonstrate a commitment to city greening and the significance of biophilia and biophilic design planners, developers and designers may be less inclined to incorporate these designs. Already, these 6 findings and possible obstacles overlap with some of the obstacles identified in the literature review. Each of these obstacles will be compared against the responses from the key informant surveys. Similar identification in obstacles will not only suggest the relevance of these issues within Toronto but will also help identify the significance and prevalence of these issues more generally. 


\section{CHAPTER 5: SURVEYS}

This chapter summarizes the results of four key informant surveys involving opinions from planning, developing and design professionals in Toronto. It provides an overview in five areas: professional awareness of biophilic design, identified strengths and weaknesses of it, the significance of nature, incentives and potential opportunities that may impede or support biophilic design and finally a rankbased question focused on the importance of the 14 Patterns of Biophilic Design.

\subsection{Awareness and Perceptions of Biophilic Design}

There was evident consensus across survey respondents in their understanding of what biophilic design is. Each identified that it aims to integrate and incorporate elements of the natural world (plant and animals) into the design of the built environment. Respondents noted that biophilic design was both a "challenge" and "philosophy" for introducing nature into urban settings. From an implementation perspective, it was interesting to note that all respondents had heard of biophilic design before and were similar in their definitions of it.

Interestingly, all four respondents stated that biophilic design is successful in providing both psychological and environmental benefits. Three further agreed that biophilic design successfully fosters an increased connection to nature, which creates improvements to human productivity, mood, mental and physical health, alongside significant supports for enhancing local biodiversity and reducing urban heat island effects.

One designer more specifically said the strengths of biophilic design were,

"improved air quality, and access to natural light. A closer relationship with nature within the built environment. Biodiversity and enhanced urban habitat. Urban heat island mitigation. Reduced stress. Improved cognitive function, mood, mental and physical health".

This respondent not only knew what biophilic design was but was able to clearly articulate the range of benefits it can provide to cities. Overall, it was clear the respondents understood the root motivations and potential of biophilic design. Excepting economic contributions, they collectively referenced the other three benefits of biophilia and biophilic design outlined in the literature review.

The respondents all additionally felt that urban residents recognized and appreciated the need for biophilic design. Respondents; however, noted that this appreciation likely centers on the less tangible benefits of biophilic design and on a more subconscious level of understanding including "improved productivity, mood, outlook and quality of life". 
This idea was confirmed in the response of another planner who noted that:

"While many consumers are not familiar with the concept of biophilic design specifically, from my experience, consumers generally demonstrate an appreciation for specific biophilic design responses and interventions, and studies have shown that the benefits are felt on a subconscious level".

Surprisingly, only one planner noted that they felt people appreciated the "aesthetic improvements and feeling [of attaining] a closer connection to nature".

Responses surrounding the weaknesses of biophilic design were much more divergent. Two respondents indicated that the weaknesses of biophilic design were tied to economics. One planner highlighted the significant costs associated with "upfront construction (capital)" and "long-term maintenance (operational)", while the other noted that biophilic design "often fails to account for life cycle costing of integrating and maintaining biophilic elements alongside hard infrastructure". Financial pressures, in commonality with literature were clear concerns among the professionals. They were additionally noted from a consumer perspective, where two respondents suggested consumers may negatively react to biophilic design because of long-term maintenance costs that were not planned for during design.

One respondent noted that on-site flora and fauna may introduce other unique property impacts, for example risks of "property damage due to the failure of irrigation systems, plant overgrowth, etc.". These ideas allude to additional and unpredictable economic costs that may be inflicted by biophilic design. In the same sense, a planner noted that "not every context provides a practical setting for biophilic design in the sense of repeated and reinforced connections with nature, which includes plants and animals". Consumers in some contexts may not appreciate biophilic design because it could protrude on the surround space or detract from the existing neighbourhood character or design of a space.

Two respondents specifically noted that biophilic design is associated with potential risk of "introducing insects or other fauna" to urban building envelopes. Concerns notably centered on the risk of "allergies associated with pollinator plants and other flora" rather than concerns from bio-phobia as referenced previously. Plant-based allergies or the introduction of insects or other fauna was similarly identified by two respondents as one reason individual citizens may be less inclined to support biophilic design. Remarkably, the capacity of greening to negatively contribute to human health and well-being in this sense was something that had not been raised in previous chapters.

From an ethical perspective, one designer noted that biophilic design concerningly "places human needs above those of all other life forms". On the one hand, this designer presented a uniquely bio-centric lens but followed this statement by saying that, "in resetting a connection with them, they are still to benefit 
more than the status quo". This designer was able to address a potential weakness of biophilic design with a clear justification.

\subsection{Existing Successes and Challenges for Nature in Toronto}

Respondents highlighted an array of ways that Toronto currently and successfully integrates nature in the city. They also referenced potential challenges and alluded to ways that the city could better integrate biophilic design in the urban realm.

To begin with, two respondents noted the successful use of local planning and policy to successfully integrate natures in the city. As this planner explained at length, Toronto currently and successfully integrates nature through:

"City-wide policies, regulations and standards (i.e. Official Plan policies, Toronto Green Standard, Parks and Recreation Facilities Master Plan, Resilient TO), through area-specific policies, regulations and standards (i.e. Secondary Plans, Precinct Plans, Public Realm Plans, Toronto Ravine Strategy), through collaborations with land developers to incorporate new parks and open spaces into large-scale developments (i.e. Corktown Commons, City Place Park), through the acquisition and designation of new land expressly for the purpose of developing new parks and open spaces (i.e. Rail Deck Park). Through collaborations with philanthropists and sponsors to convert under-utilized and/or forgotten urban spaces into new parks and open spaces (i.e. The Bentway) and through collaborations with arms-length government entities (i.e. Waterfront Toronto / Toronto Region Conservation Authority) to implement improvements to the natural heritage system (i.e. Re-Naturalization of the Don River Mouth, Leslie Street Spit / Tommy Thompson Park)."

Interestingly, this respondent alongside the others indicated that Toronto's success in integrating nature stems from both the maintenance and longevity of existing natural spaces alongside successfully solidifying park spaces throughout the city. They did not highlight the city's capacity to foster connections between nature and the built environment. For example, one planner noted that the City is effective at "developing new parks and open spaces and reinvesting in existing parks and open spaces" while another suggested the city "has long benefited from the ravine system and other natural elements, which already existed" but fails to "integrate new natural elements, particularly along parks and boulevards.

Two of the respondents felt that beyond the successful use of local planning and policy highlighted above, that they city has gradually become better at "establishing partnerships with private land developers, major institutions and private donors / philanthropists". These relationships have been key to integration especially as more "land developers realize that the market is beginning to demand these types of improvements". 
The respondents then revealed some reasons and obstacles that may be preventing the implementation of biophilic design in Toronto. A reoccurring opinion pertained to its feasibility. Respondents collectively identified that there are still "financial and regulatory hurdles" where "initial cost is one concern, but long-term costs, especially ownership fees, tend to be even more important. One individual explained this issue further and proposed that:

"developers will not see the loss of profit from full development as a smart option, regardless of whether their property is suitable. The obstacles obviously stem from "business as usual" and a developer's need to capitalize fully on development in dollar terms. That is where city or regional policy needs to step in and mandate "equitable" development."

In a similar capacity one respondent suggested biophilic design is something that will realistically appeal to,

"the sub-set of developers whose business models and proforma strategies are centered on retaining long-term ownership" on the basis that they can more accurately predict, respond to and ultimately effect up the additional borne costs of biophilic design."

These responses highlighted that the anticipated long-term maintenance costs coupled with known upfront development costs make it difficult for typical developers to afford and integrate biophilic design.

Integration ultimately requires more explicit and supportive regional and city policy or a larger variety of financial mechanisms to influence use.

Beyond evident economic impediments relating to development and maintenance, incentives were a key identified obstacle to implementation. Two respondents suggested that in Toronto there is an "absence of incentives at the municipal level" in which to encourage biophilic design. One of these respondents explained their rational in suggesting this issue could be mitigated,

"through updates to the Toronto Green Standard and direction to secure funding for biophilic design interventions through Section 37 (height and density bonusing), 41 (site plan control) and Section 42 (parkland dedication) requirements as well as the City's public art contribution requirements."

Beyond economic obstacles to implementation, one respondent suggested biophilic design is impacted by current trends in the built environment of Toronto. This respondent said:

"Since mid-century development has focused on an outward migration from the downtown, to the point of making "isolated" buildings in the landscape that are not connected at street level, except by car. Only recently has there been an attempt to redefine the downtown core, but to the point of unsustainable density and radically shrinking standards by developers in what constitutes "modern" housing in terms of size - that is, apartments and condominiums are getting smaller and smaller, and take on increasingly unorthodox configurations." 
This respondent suggests that biophilic design in Toronto is limited because most "parcels are too small to make an effective intervention or cannot be "re-connected" with natural areas, such as the ravines" and was limited in suggesting ways this could be mitigated or improved.

\subsection{Potential Change and Progress}

Having discussed some of the obstacles to biophilic design alongside trends in the presence of nature locally, it was evident that respondents agreed on ways these obstacles could be overcome. The first finding focused on consumer interest. Three respondents indicated that client request or interest in biophilic design would help increase implementation as "most clients have already decided what they 'want' by the time they hire an architect or landscape architect". Further "it helps when the client understands and appreciates the value of biophilic design" because it validates the intent and innovation of designers and planners.

Alternatively, other respondents suggested that through the early stages of adoption it may be more effective for cities to mandate rather than incentivize biophilic design as a reverse strategy to gain momentum and "impose" it on clients, rather than wait for their request. However, if incentivizing is used it should come through existing planning regulations that offer unique benefits to developers such as Section 37 benefits, as indicated by another planner previously.

All three more specifically highlighted if Toronto was part of a Biophilic Cities Network, biophilic design would be more likely. Each presented different reasoning ranging from the fact that "developers will appreciate prestige" to the value of "access to a network and unique tools to promote biophilic design". However, despite evident interest and significance of this network, two respondents noted that involvement in the network would still "require overarching planning policy that would require necessary changes, introduce financial incentives and lead to the implementation of biophilic design strategies". In keeping with the cases discussed in Chapter 4, this was interesting because analysis of the cases identified that involvement in entities like the Biophilic Cities Network does have a realistic, if not, theoretical impact on promoting biophilic design.

\subsection{Biophilic Design Principles}

Respondents were then asked about the 14 Patterns of Biophilic Design presented by Terrapin Bright Green as a 'toolkit' for the application of biophilic design. Remarkably; however, only 1 of 4 respondents had ever heard of these Patterns. Despite the small study group, the lack of awareness about the biophilic design principles may suggest that integration of biophilic design, in the realm of encapsulating all 14 Patterns, may be limited by a lack of understanding and education. 
The 14 Patterns were developed as a way to articulate how the well-researched relationships between humans and nature can be applied in the design of built environments, such that people can experience the benefits of biophilia. Yet, if professionals are unaware of these patterns as identified in this survey, this may be an obstacle to implementing application.

By way of a Likert scale ranking it was interesting that despite a lack of direct awareness of these Patterns, all respondents weighted the individual importance of each pattern relatively positively. On a scale of 1-5, 1 being not important and 5 being very important, each pattern except for three were ranked as either neutral, important or very important by all respondents. Of the 14 , non-visual connection with nature, mystery, and risk and peril were the three patterns ranked as not important by one respondent. Interestingly, these patterns although evidenced in many of the case studies analyzed, are often less deliberately incorporated. Rather, they are often apparent in many biophilic design examples and case studies as an indirect product of other patterns. This may in part explain why they were not ranked as important by all respondents. Overall, these rankings suggest that professionals do understand and appreciated the capacities of each of these patterns, and further highlight that education or a lack of awareness may be the limiting factor of use. 


\section{CHAPTER 6: CONCLUSIONS AND RECOMMENDATIONS}

The literature review, case studies and key informant surveys have identified a range of obstacles that may be impeding the integration of biophilic design in Toronto.

From a high-level, each stage of investigation has outlined that the implementation of biophilic design is reliant on both consumer and professional awareness and interest. If people, specifically the local market, do not want or seek these developments and spaces, there is nothing to drive development. Professionals, more specifically planners and developers, need this type of assurance to spark interest and validate that these types of designs will be appreciated, utilized and desired by the local public.

The literature review more uniquely identified that obstacles for implementation may extend from local and growing trends in bio-phobia and a lack of quantifiable information to demonstrate the economic, social and health benefits of biophilic design at local scales.

Cases further identified that cities like Toronto may be struggling to implement biophilic design because of a lack of supportive planning and policy in addition to lack of incentives to promote and encourage implementation. This obstacles was further raised by local survey that suggested incentives are likely a key way guide and reward implementation, recognizing the innovations and unique efforts of select planners and designers. Global analysis additionally suggested that cities with local politicians and political agendas that support and promote biophilic design generally experience wider implementation. Reoccurring obstacles also appeared throughout all phases of this research. Among the most substantial was economic concerns of implementation; specifically, upfront capital construction costs and long-term maintenance costs. Toronto, more specifically local politics and planning needs to identify how to make biophilic design more economically viable in order to influence and incentivize adoption.

This research confirms that there are evident obstacles implementing biophilic design in Toronto. With this in mind, 9 recommendations have emerged. If implemented or considered, they may assist in providing Toronto and other cities with high-quality and valuable biophilic design.

\section{Make Consumer Education a Priority}

A key way to influence the implementation of biophilic design is through consumer education. If local urban residents of the city become more aware of the mental, physical, psychological and environmental benefits of biophilic design then clients will begin to request and expect biophilic design locally. 
2. Establish Targeted Educational Programs for Developers, Planners, Designers and Other Professionals

The capacity to build, integrate and employ biophilic design is not something local professionals inherently know how to do. It would therefore be beneficial for the City to support targeted educational programs that showcase biophilic design and educate professionals about innovative techniques, strategies and approaches for implementation. This type of approach was used in Singapore through the development of the Center for Urban Greening and Ecology (CUGE), which not only promotes greenery in the city but also helps train landscape workers on new or developing green strategies. These programs and facilities will assist in mitigating professionals' apprehension to experiment with biophilic design and will exemplify the city's larger commitment to integration.

Education is also important in teaching and enabling urban planners to rediscover the ability for city and building design to advance human health and the ultimate resilience of spaces. In other words, the capacity for biophilic design to improve the city's capacity to improve resource efficiency and energy consumption, alongside larger climate change goals.

\section{Integrating with an Established Network like the Biophilic Cities Network}

In order to promote the importance of biophilic design, the city should focus on integrating into larger networks; specifically, the Biophilic Cities Network. In being a part of a Network, the City of Toronto will demonstrate their commitment to local greening, sustainability and innovative design approaches. It is also demonstrated that many developers and planners will appreciate the prestige that comes with affiliating with larger entities.

\section{Elect Creative, Energetic Councillors and Politicians Who Value Nature}

Politicians have a tremendous capacity to shape the public realm. They can influence the development process, advocate for certain causes and encourage certain ideas. It is important for the City of Toronto, and local people, to advocate for politicians that value green space and nature, are innovative, committed to local well-being and are visionary, such that they will be more inclined to encourage the adoption of biophilic design.

\section{Focus on Financing Incentives}

Overcoming economic barriers to implementation relies on finding and developing a revenue formula that helps leverage and provide financing mechanisms. This could be done through existing policy and planning regulations or through the development of new ones. 
Singapore, for example, developed the Skyrise Greenery Incentive Scheme to support the city's goals in becoming a more sustainable city. As mentioned, Skyrise Greenery provides generous subsidies (up to $50 \%$ ) for installations of green walls, green rooftops, sky parks and terraces and other green elements of various sorts. Toronto could extend incentive schemes like the existing Green Roof Pilot Incentive Program to support larger scale and more innovative applications of local biophilia. This would not only emphasize local support and city interest but would help enhance the quantity and variety of green in the city. Integration could also be supported in allowing biophilic design to offset other fees associated with new developments such as the Parks Levy Fee, or cash required by new developments in lieu of parkland dedication. Doing so would help to recognize the added costs associated with employing biophilic design while accounting for the additional greening it provides.

Toronto could also focus on utilizing existing planning and policy instruments to support the implementation of biophilic design. On the basis that biophilic design like other green spaces, would likely increase surrounding property values, the City of could consider utilizing tax increment-based financing. To this regard, the higher tax revenues generated from the integration of biophilic design could be used to offset both the initial and long-term maintenance costs associated with biophilic design. The funding would help subsidize the added fees associated with these developments.

Funding for biophilic design could also be promoted through other policy's such as Section 37: Height and Density Bonusing. If the city effectively recognized biophilic design as a public benefit, integration could be exchanged for increased floor area or height on a given property. In doing so, developers would benefit from the financial capacities associated with a larger building envelope, while the city would benefit from the environmental, economic and health benefits provided through inclusion.

\section{Establish and Maintain Partnerships}

Fostering and sustaining partnerships with private land developers, unique architects and designers, major institutions, private donors and philanthropists who understand and appreciate the importance of biophilic design is valuable in expediting integration. Toronto has already begun to do this in supporting and developing relationships with global design entities including Brisbin Brook Beynon Architects and Denmark's Bjarke Ingels group who each bring innovative biophilic designs to the city. By establishing and supporting these relationships, it will become easier for biophilic design to filtrate into the local urban environment and will simultaneously demonstrate opportunity and viability to other professionals. 


\section{Integrate Biophilic Language in Local Policy}

Toronto should consider introducing language centered on biophilic design into the City's park land dedication and public art requirements for new development. This will not only identify city commitment to biophilic deign but it will also make individuals more familiar and exposed to the concept.

\section{Consider Spending Parkland Dedication Reserve Funds on Biophilic Design}

New Toronto developments, under Section 42 of the Planning Act, are required to contribute a piece of their land for park space or alternatively can contribute cash-in-lieu of land that is designed to support alternate park purchase and improvements. In order to incentivize biophilic design, Toronto could consider integrating biophilic design within this provision. Biophilic design could for example help reduce the cash-in-lieu fee such that it is providing green elements. Alternatively, it could be used to justify reductions in the amount of parkland a new development is required to dedicate. Each aim to reduce financial losses to developments, while recognizing that with increasing vertical building, this may actually amount to the provision of more green elements throughout the city.

The City could also consider utilizing cash-in-lieu of parkland money to support the financing of biophilic design elements such as green roofs or vertical greening. Not only would this help utilize existing and abundant cash collected from high-cost development sites in the city, but it would also help ensure that collected money is being used proximally to where it was collected. It would further assist in ensuring that biophilic design and its benefits are equally accessible and useable in all built environments, an important mechanism for ensuring biophilic design does not contribute to an inequitable distribution of nature in cities.

\section{Integrate Strategies for Implementation Within Existing Policies}

If Toronto is keen to enhance the integration of biophilic design locally, it would be beneficial to develop a clear and articulate implementation strategy. The City of Chicago, more specifically the collaboration of over 8 City departments, enacted the Adding Urban Green to Urban Design Plan. This plan provides a clear economic and environmentally sound planning and design framework to promote and regulate the use of green elements in local design. Toronto would benefit from a similar planning framework. It would assist in providing consistent direction for city professionals and would help guide council decisions surrounding public investment and improvements to the local built environment.

This paper has sought to identify and explore obstacles to the implementation of biophilic design in Toronto. Biophilic design represents a prime way to enhance human well-being through improved mental and physical health, local intelligence and creativity, by fostering more humane and more generous 
interactions, and by positively contributing to the local economy. It goes further in its capacity to increase the sustainability of local and global built environments, especially urban areas that are increasingly defined by growing populations, ongoing densification and development.

As elsewhere, Toronto can benefit from biophilic design as a means to sustain, increase and creatively insert nature in the city, while supporting and maintaining continued growth and development. That being said, this major research paper has identified what and why particular obstacles are impeding the application of biophilic design throughout the city. These obstacles range from a lack of incentives and economic provisions, an absence of knowledge and expertise, bio-phobia, unfamiliarity or lacking awareness, and a gap in supportive or directive planning and policy. In recognition of these obstacles, 9 recommendations were provided. These recommendations aim to recognize the unique context of Toronto, reflect and build upon existing policy, implement and extend upon global successes and importantly focus on responding to and addressing the key obstacles identified.

In a time where growth is rapid, and development is ongoing, cultivating and embracing new and powerful ways to integrate nature in cities will be necessary. Such ways have been evidenced by the various case studies discussed, where cities like Melbourne, Australia and Chicago have intentionally begun integrating nature more explicitly in their built environments. Each have worked to rally local citizens around the need for a design shift by promoting and enhancing the role of biophilic design in local politics and right through to smaller citizen run advocacy groups. Biophilic design is a key way maintain local greening and help support humans undoubting response and connection to nature. In some way, the obstacles outlined in this paper identify serious challenges that will be faced for Toronto and any city looking to enhance urban biophilia. The good news is that they also identify ways for the city to reimagine what life in Toronto could look like, how they can incentivize and influence development and suggests how the city might better connect people and the built environment, to the natural world. 


\section{CHAPTER 7: BIBLIOGRAPHY}

ADR, 2017. Biophilic design built into new Melbourne Metro stations. Australian Design Review. Retrieved from https://www.australiandesignreview.com/architecture/biophilic-design-built-newmelbourne-metro-stations/

Annerstedt, M \& Währborg, P. (2011). Nature-assisted therapy: systematic review of controlled and observational studies. Scand. J. Public Health: 1-18.

Aliento, W. (2017) Melbourne's trains may soon glide into new biophilic precincts. The Fifth Estate. Retrieved Jan $15^{\text {th }}, 2019$ from https://www.thefifthestate.com.au/innovation/buildingconstruction/melbournes-trains-may-soon-glide-into-new-biophilic-precincts/

Arch Dailey. (2018). One Central Park. Retrieved from https://www.archdaily.com/551329/one-centralpark-jean-nouvel-patrick-blanc/54245770c07a80548f00007f-one-central-park-jean-nouvel-patrick-blancphoto

Architizer (2007). Newton Suites.

Architizer. (2019). 158 Cecil Street Singapore. Architizer. Retrieved from

https://architizer.com/projects/158-cecil-street-singapore/

Architizer. (2019). Newton Suites Singapore. Architizer. Retrieved from

https://architizer.com/projects/newton-suites-singapore/media/171334/

Atchely, R; Strayer, D \& Atchley, P. (2012). Creativity in the Wild: Improving Creative Reasoning through Immersion in Natural Settings. PLoS ONE. 7(12).

Barton, J; Pretty, J. (2010). What is the best dse of nature and green exercise for improving mental health? A multi-study Analysis. Environmental Science and Technology 44: 3947-3955.

Bascaramurty, D (2017). Density, infrastructure and the high cost of building a vertical Toronto. The Globe and Mail. https://www.theglobeandmail.com/news/toronto/density-infrastructure-and-the-highcost-of-building-a-vertical-toronto/article4610721/

Biophilic Cities. (2019) What is a biophilic city? Biophilic Cities. Retrieved October $5^{\text {th }}, 2019$ from http://biophiliccities.org/

Bladwin, E. (2018). BIG's King Street West Condo Community Approved for Development in Toronto. $B I G$. Retrieved from https://www.archdaily.com/902156/bigs-king-street-west-condo-communityapproved-for-development-in-toronto

Beatley, T. (2011). Biophilic Cities: Integrating Nature into Urban Design and Planning. Washington, D.C: Island Press.

Beatley, T \& Newman, P. (2013). Biophilic Cities are Sustainable, Resilient Cities. Department of Urban and Environmental Planning 5 (8): 3328-3345.

Beatley, T. (2017). Handbook of Biophilic City Planning and Design. Washington, D.C, Island Press.

Bell, JF; Wilson, JS; Liu, GC. (2008). Neighbourhood greenness and 2-year changes in body mass index of children and youth. NCBI 35(6): 547-53.

Benyus, J. (2002). Biomimicry: Innovation Inspired by Nature. Harper Collins. 
Benyus, J. (2008) A Good Place to Settle: Biomimicry, Biophilia and the Return of Nature's Inspiration to Architecture. IN: S, Kellert, J, Herrwegen \& M, Mador eds., Biophilic Design, Hoboken. NJ: John Wiley and Sons, 27-42.

Berman, M; Jonides, J; Kaplan, S. (2008). The cognitive benefits of interacting with nature. Psychological Science Sage Journals 10.

Birkeland, J. (2016). Net Positive Biophilic Urbanism. Smart and Sustainable Built Environment. Bingley 5(2): 9-14.

Boger, S., \& Beyer, KM. (2016) Green Space, Violence and Crime: A Systematic Review. US National Library of Medicine 17(2): 160-71.

Bowler, D., Buyung-Ali, L, Knight, T., Pulin, A. (2010). A systematic review of evidence for the added benefits to health of exposures to natural environments. BMC Public Health: 10

Browning, B., Garvin, C., Fox, B \& Cook, R. (2014) Why designing with nature in mind makes financial sense. Terrapin Bright Green. Retrieved October $17^{\text {th }}, 2018$ from

http://www.terrapinbrightgreen.com/wp-content/uploads/2012/06/The-Economics-of-Biophilia_TerrapinBright-Green-2012e.pdf

Bullen, J. (2015). More trees on your street help you feel younger. Retrieved from www.smh.com.

Buzzell, L; Chalquist, C. (2009). Ecotherapy: Healing with nature in mind. San Francisco: Sierra Club Books.

Cama, R. (2009). Evidence-based Healthcare Design. Hoboken, NJ: John Wiley.

Campbell, J. (2017). Biophobia: On Raising a Generation of Nature-Phobic Kids. Children and Nature Network. Retrieved February 1 $1^{\text {st }}, 2019$ from https://www.childrenandnature.org/2017/11/15/biophobia-onraising-a-generation-of-nature-phobic-kids/

Capaldi, C., Dopko, R \& Zenenski, J. (2015). The relationship between nature connectedness and happiness: a meta-analysis. Carleton Department of Psychology. Retrieved October $5^{\text {th }}, 2018$ from https://www.frontiersin.org/articles/10.3389/fpsyg.2014.00976/full

Chiang, K., \& Tan, A. (2009). Vertical Greenery for the Tropics. Singapore: National Parks Board, Singapore Botanical Gardens and Building and Construction Authority.

Chicago Architecture Center. (2009). Aqua. Retrieved from

http://www.architecture.org/learn/resources/buildings-of-chicago/building/aqua/

Chicago Center for Green Technology (2019) Welcome to the Chicago Center for Green Technology.

Chicago, USA. Retrieved on February $21^{\text {st }}, 2019$ from www.chicagogreentech. org/

Chicago City Place Plan. (1997).

City of Chicago (2019) Greencorps Chicago. Chicago, USA. Retrieved on February $16^{\text {th }}, 2019$ from www.cityofchicago.org/city/en/depts/cdot/provdrs/conservation_outreachgreenprograms/svcs/greencorps _chicago.html

City of Chicago (2008) Adding Green to Urban Design, A City for Us and Future Generations. Chicago, USA. 
City of Melbourne. (2007) Greening Your Building: A Toolkit for Improving Asset Performance. City of Melbourne City Council. Retrieved February 5 ${ }^{\text {th }}, 2019$ from https://www.melbourne.vic.gov.au/SiteCollectionDocuments/greening-your-building-toolkit.pdf

City of Melbourne. (2017). Nature in the City: Thriving Biodiversity and Healthy Ecosystems. City of Melbourne City Council. Retrieved February 5 ${ }^{\text {th }}, 2019$ from https://www.melbourne.vic.gov.au/SiteCollectionDocuments/nature-in-the-city-strategy.pdf City of Sydney. (2017). Environmental Action Strategy and Action Plan. City of Sydney. Retrieved February $5^{\text {th }}, 2019$ from https://www.cityofsydney.nsw.gov.au/_data/assets/pdf_file/0007/284749/Environmental-Actionstrategy-and-action-plan.pdf

Clay, R. (2001). Green is good for you. Monitor on Psychology 32(4): 40-42.

Clayton, S. (2012). The Oxford Handbook of Environmental and Conservation Psychology. New York, Oxford University Press.

Cox, D; Shanahan, D; Hudson, H; Plummer, K; Siriwardena, G; Fuller, R; Anderson, K; Hancock, S; Gaston, K. (2017). Doses of neighbourhood nature: the benefits for mental health of living with nature. BioScience 67(2): 147-155.

Daley, D. (2010). ADHD and academic performance: why does ADHD impact on academic performance and what can be done to support ADHD children in the classroom? Child: Care, Health and Development 36(4).

Donovan, G; Burty, D. (2010). Trees in the City: Valuing street trees in Portland, Oregon. Landscape and Urban Planning 94: 77-83.

Donovan, G et al. (2011) Urban trees and the risk of poor birth outcomes. Health and Place 17: 390-393.

Downton, PF; Jones, DS; Zeunert, J \& Roös, PB. (2016). Biophilic Design Applications: Putting Theory and Patterns into Built Environment Practice. Australia. KNE Publishing.

Downton, PF; Jones, DS; Zeunert, J \& Roös, PB. (2017). Creating Healthy Places: Railway Stations, Biophilic Design and the Metro Tunnel Project. Melbourne: Melbourne Metro Rail Authority. Retrieved from https://apo.org.au/sites/default/files/resource-files/2017/11/apo-nid130036-1235431.pdf

Durnbaugh, A. (2012) Personal Communications, Director of Sustainability, Loyola University Chicago, Center for Urban Environmental Research \& Policy and Former Deputy Commissioner of Natural Resources and Water Quality, Department of Environment, City of Chicago.

Feda, D.M; Seelbinder, A; Baek, S; Raja, S; Yin, L; Roemmich, J.N. (2015)Neighbourhood parks and reduction in stress among adolescents: Results from Buffalo, New York. Indoor and Outdoor Built Environment 24(5): 631-639.

Friedmann, E. (1983). Animal-human bond: health and wellness. IN A. Katcher \& A. Beck, eds., New Perspectives on Our Lives with Companion Animals. Philadelphia: University of Pennsylvania Press.

Friendly Built Environment. (2018). Khoo Teck Puat Hospital. Friendly Buildings. Retrieved from https://friendlybuildings.bca.gov.sg/buildingdetail.html?title=Khoo\%20Teck\%20Puat\%20Hospital\%20\&id=1f87b92e-7308-41c2-9eca-a81f75c5e84c 
Frumkin, H. (2001). Beyond toxicity: human health and the natural environment. American Journal of Preventive Medicine 20.

Frumkin, H. (2008). Nature contact and human health: building the evidence base. In, S, Kellert, M Heerwagen, \& M, Mador. Biophilic Design: The Theory, Science, and Practice of Bringing Buildings to Life. Hoboken, NJ: John Wiley.

Gang, J. (2016). Aqua Tower. Studio Gang. Retrieved on February 15 ${ }^{\text {th }}, 2019$ from http://studiogang.com/project/aqua-tower

Getter, K \& Rowe, DB. (2006) The Role of Extensive Roofs in Sustainable Development. HortScience 41(5): 1276-1285.

Girling, C \& Kellert, R. (2005). Skinny Streets and Green Neighbourhoods. Design for Environment and Community, Washington, DC: Island Press.

Grant, A. (2017). 1 year out: Toronto leaders talk about the biggest challenges facing our city. Retrieved February $15^{\text {th }}$, 2019 from http://www.cbc.ca/news/canada/toronto/toronto-leaders-talk-about-biggestchallenges-facing-city-1.4363906

Green, J. (2012). Biophilic building design held back by lack of data. THE DIRT. Retrieved from https://dirt.asla.org/2012/05/23/biophilic-building-design-held-back-by-lack-of-data/

Green Roofs (nd) Chicago City Hall, Green Roofs Project Database, Green Roofs North America. www.greenroofs.com/projects/pview.php?id=21

Grinde B., Patil G. (2009). Biophilia: Does Visual Contact with Nature Impact on Health and WellBeing? National Library of Medicine, US.

Han, KT. (2003). A reliable and valid self-rating measure of the restorative quality of natural environments. Landscape and Urban Planning 64(4): 209-232.

Harlow, K. (2019). 7 Innovative architectural ideas with world-changing potential. Mental Floss. Retrieved from http://mentalfloss.com/article/91686/innovative-architectural-designs

Hassen, N. (2016). Green space in the city: How Toronto's green space helps promote mental health. Wellesley Institute. Retrieved from http://www.wellesleyinstitute.com/healthy-communities/green-spacein-the-city-how-torontos-green-spaces-promote-mental-health/

Heerwagen, J. (2009) Biophilia, Health and Well-being. IN: L, Campbell \& A, Wiesen. Restorative commons: creating health and well-being through urban landscapes. Newtown Square, PA: U.S. Department of Agriculture, Forest Service, Northern Research Station 39-58.

International Living Future Institute. (2019). Healing through nature: Khoo Teck Puat hospital. Living Future. Retrieved on November 12 ${ }^{\text {th }}, 2019$ from https://living-future.org/biophilic/case-studies/awardwinner-khoo-teck-puat-hospital/

Landry, S., \& Northrop, R., Andreu, M., \& Rhodes, C. (2013). City of Tampa 2011 Urban Forest Analysis: The Structure, Composition, Function and Economic Benefits of Trees and the Urban Forest. City of Tampa, Florida.

Louv, R. (2008). Last Child in the Woods. Workman Publishing, New York. 
Louv, R. (2012). The Nature Principle: Reconnecting with Life in a Virtual Age. Chapel Hill: Algonquin Press.

Kaplan, S. (1995). The restorative benefits of nature: toward an integrative framework. Journal of Environmental Psychology 15: 169-182.

Kardan, O; Gozdyra, P; Misic, B; Moola, B; Palmer, L; Paus, T \& Berman, M. (2015). Neighbourhood greenspace and health in a large urban center. Springer Nature Publishing 5: 11610.

Kellert, S. (1997). Kinship to Mastery: Biophilia in Human Evolution and Development. Washington, DC: Island Press.

Kellert, S., \& Wilson, E. O. (eds.). (1993). The Biophilia Hypothesis. Washington, DC: Island Press.

Kellert, S. (2005) Building for Life: Designing and Understanding the Human-Nature Connection. Washington, DC: Island Press.

Kellert, S; B. Finnegan. (2011) Video: Biophilic Design: The Architecture of Life. Retrieved from www.bullfrogfilms.com

Kellert, S., Heerwagen, M., Mador, eds. (2008). Biophilic Design: the Theory, Science, and Practice of Bringing Buildings to Life. Hoboken, NJ: John Wiley.

Kellert, S. \& J. Heerwagen. (2007). Nature and healing: the science, theory, and promise of biophilic design. In Guenther, R. and G. Vittori, eds. Sustainable Healthcare Architecture. Hoboken, NJ: John Wiley.

Kellert, S \& Calabrese, E. (2015) The Practice of Biophilic Design. Retrieved on September $5^{\text {th }}, 2018$ from www.biophilic-design.com

Kellert, S. (2016). Biophilic Urbanism: The potential to transform. Smart and Sustainable Environment $5(1), 4-8$.

Khoo Teck Puat Hospital. (2019). KTPH. Retrieved from https://www.ktph.com.sg/main/home

Kilkenny, C. (2015). Biophilic Design Gaining Ground in Canada. Retrieved on November $5^{\text {th }}, 2018$ from www.rcinet.ca/en/2015/05/20/biophilic-design-gaining-ground-in-canada/

Klepeis, N., Nelson, W., Ott, W., Robinson, J., Tsnag, A., Switzer, P., Behar, J., Hern, S., \& Engelmann, W (2001). The National Human Activity Pattern Survey (NHAPS): a resource for assessing exposure to environmental pollutants. Journal of Exposure Analysis and Environmental Epidemiology, 11: 231-252.

Kuo, F \& Taylor, A. (2003). A potential natural threat for attention-deficit/hyperactivity disorder: Evidence from a national study. American Journal of Public Health 94 (9): 1580-1596. https://ajph.aphapublications.org/doi/abs/10.2105/AJPH.94.9.1580

Kuo, F. (2010). Parks and other green environments: essential components of a health human habitat. National Recreation and Parks Association. Washington, DC:

Kuo, W; Sullivan, W. (2011). Environment and crime in the inner city: does vegetation reduce crime? Environment and Behaviour 33: 343-367.

Kuo, W; Sullivan, W. (2004). The fruit of urban nature vital neighbourhood spaces. Environment and Behaviour 36(5): 678-700. 
LaMorte, W. (2018). Diffusion of Innovation Theory. Retrieved April 1 1 ${ }^{\text {st }}, 2019$ from

http://sphweb.bumc.bu.edu/otlt/MPH-

Modules/SB/BehavioralChangeTheories/BehavioralChangeTheories4.html

Landry, Shawn M., Michael G. Andreu, Robert J. Northrop and Carolyn C. Rhodes. (2013). City of

Tampa 2011 Urban Forest Analysis: The Structure, Composition, Function and Economic Benefits of

Trees and the Urban Forest. Final Report to the City of Tampa, September 2013. City of Tampa, Florida.

Lichtenfeld, S; Elliot, A; Maier M \& Pekrun, R (2012). Fertile Green: Green Facilitates Creative

Performance. Personality and Social Psychology Bulletin 38(6): 784-797.

Lin, B., Meyers, J., \& Barnett, G. (2015). Understanding the potential loss and inequities of green space distribution with urban densification. Urban Forestry \& Urban Greening 14(4), 952-958.

Littke, H. (2016). Becoming biophilic: Challenges and opportunities for biophilic urbanism in urban planning policy. Smart and Sustainable Built Environment 5:1.

Living Future Institute Australia. (2017). Living Building Challenge. Retrieved February $12^{\text {th }}, 2019$ from https://living-future.org.au/living-building-challenge/

Lopez, R. (2012) The built environment and public health. John Wilen \& Sons, Inc.

Lornic, J. (2015). Parks in crisis part 1: All built up and no place to go. SpacingToronto. Retrieved from http://spacing.ca/toronto/2015/04/13/parks-in-crisis-part-1-all-built-up-and-no-place-to-go/

Louv, R. (2012). The nature principle: Reconnecting with life in a virtual age. Chapel Hill, NC. Algonquin Books on Chapel Hill.

Maas, J; Verheij, S; Groenewegen, S; De Vries, S; Spreeuwenberg, P. (2006). Green space, urbanity and health: How strong is the relation? Journal of Epidemiology and Community Health 60(7) 587-592.

Maller, C; Townsend, M; Pryor, A; Brown, P; St Leger, L. (2006). Healthy nature healthy people: 'contact with nature' as an upstream health promotion intervention for populations. NiCHE 21(1): 45-54.

Marcus, C.M. and N.A. Sachs. (2014). Therapeutic Landscapes: An Evidence-based Approach to Designing Healing Gardens and Restorative Outdoor Spaces. Hoboken, NJ: John Wiley.

Matsuoka, R.H.; Kaplan, R. (2008). People's needs in the urban landscape: Analysis of landscape and urban planning contributions. Landscape and Urban Planning, 84: 7-19.

Meixian, L. (2017). Landscape replacement policy for buildings to include vertical greens, rooftop farms: URA. Business Times: Real Estate. Retrieved February 12 ${ }^{\text {th }}$, 2019 from https://www.businesstimes.com.sg/real-estate/landscape-replacement-policy-for-buildings-to-includevertical-greens-rooftop-farms-ura

Montgomery, M. (2016). Benefits of Biophilic Design Explored Through Human Ecology. URJHS 14.

Nassauer, J.I. (1995). Messy Ecosystems, Orderly Frames. NCRS Landscape Journal 14 (2).

National Parks Board. (2011). National Parks Board. Singapore Government.

National Parks Board. (2012a). Park Connector Network. Singapore Government.

National Parks Board. (2012b). Skyrise Greenery Award. Singapore Government. 
Nesbitt, L; Meitner, M; Girling, C; Sheppard, S \& Lu, Y. (2019). Who has access to urban vegetation? A spatial analysis of distributional green equity in 10 US cities. Landscape and Urban Planning 181 (51).

Newman, P. (2012). Biophilic urbanism: a case study on Singapore. Journal Australian Planner 51 (1).

Newman, P. (2012). Can biophilic urbanism deliver strong economic and social benefits in cities?

Sustainable Built Environment: National Research Centre.

Newman, P., Beatley, T., and Blagg, L (2012) Singapore: Biophilic City.

Newman, P. (2014). Biophilic urbanism: a case study on Singapore. Journal of Australian Planning 51 (1).

Newman, P. (2015) Green urbanism and its application to Singapore: A tale of seven green cities. CITYGREEN 1 (130).

Ngan, G. (2004) Green Roof Policies: Tools for Encouraging Sustainable Design, Landscape Architecture Canada Foundation, Canada.

Nouvel, J \& Beissel, B. (2014). Case Study: One Central Park, Sydney. CTBUH Journal 4.

Ohly, H; White, MP; Wheeler, BW; Bethel, A; Ukoumunne, OC; Nikolaou, V \& Garside, R. (2016). Attention Restoration Theory: A systematic review of the attention restoration potential of exposure to natural environments. US National Center for Biotechnology Information 19 (7): 305-342.

O’Neil, L. (2019) This is What Toronto's Most Ambitious New Condos Will Look Like. Retrieved February $7^{\text {th }}, 2019$ from https://www.blogto.com/real-estate-toronto/2018/12/westbank-king-torontoproject/

Orians, G. (2008) Nature and Human Nature. The MIT Press 137 (2): 39-48.

Parson, R. (1991). Empowerment: purpose and practice principle in social work. A Journal of Community and Clinical Practice 7-21.

Piff, P., Dietze, P., Feinberg, M., Stancato, D., \& Keltner, D. (2015). Awe, the Small Self, and Prosocial Behaviour. Journal of Personality and Social Psychology 108(6): 883-899.

https://www.apa.org/pubs/journals/releases/psp-pspi0000018.pdf

Pincetl, S. (2012). Nature, urban development and sustainability - what new elements are needed for a more comprehensive understanding? Center for Sustainable Urban Systems, Institute of the Environment and Sustainability 29 (2)

Plambech, T; Konijnendijk, C. (2015). The impact of nature on creativity - a study among Danish creative professionals. Urban forestry and urban greening.

Plastrik, P. (2019) The city with a garden. Next City. Retrieved January $4^{\text {th }}, 2019$ from https://nextcity.org/features/view/the-city-within-a-garden

Preston, R. (2007) The Wild trees: A Story of Passion and Daring. New York: Random House.

Przybylski, A; Weinstein, N; Ryan, R. (2009). Can nature make us more caring? Effects of immersion in nature on intrinsic aspirations and generosity. University of Rochestor: Personality and Social Psychology Bulletin. 
Reeve, A, Hargroves, K, Desha, C, Bucknum, M \& Newman, P (2011). Considering the application of biophilic urbanism: A Sustainable Built Environment National Research Centre discussion paper. Curtin University and Queensland University of Technology.

Reeve, Angela and Hargroves, Karlson and Desha, Cheryl and Newman, Peter and el Baghdadi, Omniya. (2013). Biophilic Urbanism: Harnessing natural elements to enhance the performance of constructed assets, IN S, Kajewski, K, Manley, \& K, Hampson, Proceedings of the 19th CIB World Building.

Roe, J; Aspinall, P. (2011). The restorative outcomes of forest school and conventional school in young people with good and poor behaviour. Urban forestry and Urban Greening 10(3): 205-212.

Russo, A., Escobedo, F.J., Cirella, G.T., Zerbe, S., (2017). Edible green infrastructure: An approach and review of provisioning ecosystem services and disservices in urban environments. Agric. Ecosyst. Environ 242, 53-66.

Ryan, C. (2017). Biophilic Design precedents: three perspectives on evidence and ideation. Terrapin Bright Green. Retrieved February $5^{\text {th }}, 2019$ from https://www.terrapinbrightgreen.com/blog/2017/01/biophilia-precedents-perspectives/

Ryan, R. (2000). Self-Determination Theory and the Facilitation of Intrinsic Motivation, Social Development, and Well-Being. American Psychological Association 55(1): 68-78.

Saunders, D (2018). Violent Crime has Faded in Our Cities, Replaced by Fear and Distrust. Retrieved on January $5^{\text {th }}$, 2019 from https://www.theglobeandmail.com/opinion/article-violent-crime-has-faded-in-ourcities-replaced-by-fear-and-distrust/

Schwartz, A. (2012). Why we need biophilic cities. Co Design. Retrieved from https://www.fastcodesign.com/1679821/why-we-need-biophilic-cities

Sharkey, P (2018). Uneasy Peace: The Great Crime Decline, The Renewal of City Life, and the Next War on Violence. W.W. Norton \& Company.

Slaper, T. (2011). The triple bottom line: what is it and how does it work? IBCRU 86 (1).

Sole-Smith, V. (2006). Nature on the Threshold. The New York Times. Retrieved February $5^{\text {th }}, 2019$ from https://www.nytimes.com/2006/09/07/garden/07bio.html

Steinman, D (1993). The Architecture of Illness: Millions of Workers are 'Sick of Work. Retrieved February $5^{\text {th }}, 2019$ from http://www.environmentalhealth.ca/fall93sick.html

Stepnitz, K. (2013). Pinpointing how nature's benefits link to human well-being. Science Daily. Michigan State University. Retrieved from https://www.sciencedaily.com/releases/2013/05/130522180317.htm

Studio Gang. (2019). Aqua Tower. Retrieved from http://studiogang.com/project/aqua-tower

Subramaniam, S. (2017) How Singapore is creating more land for itself. The New York Times Magazine. Retrieved January 15 ${ }^{\text {th }}, 2019$ from https://www.nytimes.com/2017/04/20/magazine/how-singapore-iscreating-more-land-for-itself.html

Taylor, A. (2001). Coping with ADD: the surprising connection to green places. Environment and Behavior 33.

Taylor, D. (2007). Growing Green Roofs, City by City. Environmental Health Perspectives 115(6): A308-A311. 
TD. (2014). Special Report: Urban Forests - the Value of Trees in the City of Toronto. Retrieved on April $1^{\text {st }}, 2019$ from https://www.td.com/document/PDF/economics/special/UrbanForests.pdf

Terrapin Bright Green LLC. (2012). The economics of biophilia: why designing with nature in mind makes financial sense. New York: Terrapin Bright Green.

The Singapore Green Plan. (2012). UN.

The Skyscraper Center. (2019) One Central Park. The Skyscraper Center: the global tall building database of the CTBUH. Retrieved January $15^{\text {th }}, 2019$ from http://www.skyscrapercenter.com/building/onecentral-park/10710

Townsend, M and R. Weerasuriya. Beyond blue to green: the benefits of contact with nature for mental health and wellbeing. Retrieved January $23^{\text {rd }}$, 2019 from www. Beyondblue.org.au

Troy, A; Grove, M; O’Neil-Dunne, J. (2012). The relationship between tree canopy and crime rates across an urban-rural gradiant in the greater Baltimore region. Landscape and Urban Planning 106(3): 262-270.

Trust for Public Land. (2014). 2014 City Park Facts. Retrieved from https://www.tpl.org/sites/default/files/files_upload/2014_CityParkFacts.pdf

Ulrich, R., Simons, R., Losito, B., Fiorito, E., Miles, M., \& Zelson, M. (1991). Stress Recovery During Exposure to Natural and Urban Environments. Journal of Environmental Psychology 11: 201-230.

Ulrich RS. (1999) Effects of gardens on health outcomes: Theory and research. In: Cooper MC, Barnes M, editors. Healing Gardens Therapeutic Benefits and Design Recommendations. John Wiley \& Sons; New York, NY, USA.

Ulrich, R. (2008). Biophilic theory and research for healthcare design. In Kellert et al., Biophilic Design: The Theory, Science, and Practice of Bringing Buildings to Life. 87-106.

Wackernagel, M \& Rees, W. (1996) Our Ecological Footprint. Gabriola Island, BC, Canada: New Society Publishers.

Wang, H; Tsunetsugn, Y; and Africa, J. (2015). Seeing the forest for the trees. Harvard Design Magazine. www.harvarddesignmagazine.org/issues/40/seeing-the-forest-for-the-trees

Ward Thompson, R; Rose, P; Mitchell, R; Clow, A; Miller, D. (2014). More green space is linked to less stress in deprived communities: Evidence from salivary cortisol patterns. Landscape and Urban Planning 105: 221-229.

Waterman, T. (2018). Beyond green building: Where architecture meets landscape. Azure Magazine. Retrieved from https://www.azuremagazine.com/article/green-buildings-architects-landscape-architects/

Weinstein, N., Balmford, A., DeHaan, C., Gladwell V., Bradbury, R., \& Amano, T. (2015). Seeing Community for the Trees: The Links Among Contact with Natural Environment, Community, Cohesion and Crime. BioScience 65(12): 1141-1153.

Wells, N. and K. Rollings. 2012. The natural environment: influences on human health and function. IN S, Clayton, S. The Oxford Handbook of Environmental and Conservation Psychology. London: Oxford University Press.

Wilson, E.O. (1984). Biophilia. Cambridge University Press. 
Wilson, E.O. (1986). Biophilia: the Human Bond with Other Species. Cambridge: Harvard University Press.

Williams, K., Lee, K., Hartig, T., Sargent, L., Williams, N., Johnson, K. (2016) Conceptualizing creativity benefits of nature experience: Attention restoration and mind wandering as complementary processes. Journal of Environmental Psychology 59: 36-45.

Wolf, K. (2005). Trees in the Small City Retail Business District: Comparing Resident and Visitor Perceptions. Journal of Forestry 103: 390-395.

Ulrich RS, Simons RF, Losito BD, Fiorito E, Miles MA, Zelson M. (1991) Stress recovery during exposure to natural and urban environments. Journal of Environmental Psychology. 11: 201-230.

Ulrich, RS. (1984). View through a window may influence recovery of surgery. NCBI 224(4627): 420-1. UN Environment. (2018) 'A city in a garden': Singapore's journey to becoming a biodiversity model. UN Environment.

United Nations. (2014). World's population increasingly urban with more than half living in urban areas. New York. Retrieved from http://www.un.org/en/development/desa/news/population/world-urbanizationprospects-2014.html

USDA, 2004.

Van der Wal, A.J.; Schade, L; Krabbendam, M. (2013). Do Natural landscapes reduce future discounting in humans? Proceedings of the Royal Society B 280:20132295.

Yok, T. P., and A. Sia. 2008. A Selection of Plants for Green Roofs in Singapore. 2nd ed. Singapore: Centre for Urban Greenery and Ecology, National Parks Board.

Young, R. F. (2016). The Biophilic City and the Quest for Paradise. Smart and Sustainable Built Environment 5(1): 25-46.

Zadeh, R; McCuskey, M; Williams, G \& Chung, S. (2014). The Impact of Windows and Daylight on Acute-Care Nurses' Physiological, Psychological, and Behavioral Health. Health Environment Research and Design Journal.

Zadeth, RS. (2014). The impact of windows and daylight on acute-care nurses' physiological, psychological and behavioural health. Health Environments and Research Design Journal.

Zelenski, J; Dopko, R; Capaldi, C. (2015). Cooperation in in Our Nature: Nature exposure may promote cooperation and environmentally sustainable behaviour. Journal of Environmental Psychology 42: 24-31. 